\title{
A Systematic Review of Cannabidiol Based Dosage Forms
}

Alexander J. Sperry, Tarik Youssef, Yen Tuong, Abhay S. Chauhan*

Medical College of Wisconsin School of Pharmacy, 8701 W. Watertown Plank Rd, Milwaukee, WI 53226

\section{Graphical abstract}

\section{What drug delivery systems are being employed to administer CBD in the practical setting?}

\section{Methods}

- PubMed Clinical Queries: $n=458$

- Google Scholar: n=297

- Articles were excluded based on title and abstract applicability.

- Included from PubMed: $n=31$

- Included from G. Scholar: $n=6$

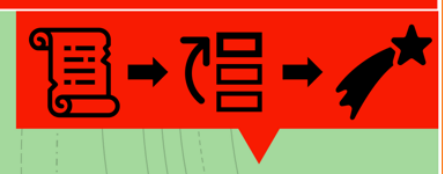

\section{Findings}

- Reviews of Conventional,

Transdermal, Emulsion-based, Nanoparticle-based Dosage Forms $(n=37)$

- Plausibility of emulsion and nanoparticle-based formulations in future uses.

- Interesting directions for future clinical and experimental research.

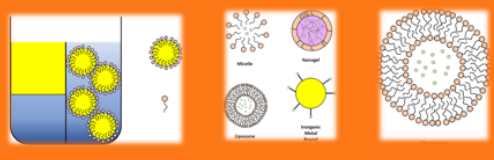

\section{Themes}

- Increased max serum concentrations, and decreased time to max concentration in nanoparticle and emulsion formulations.

- Experimental therapeutic applications of cannabinoids.

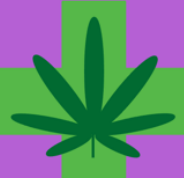

\section{Abstract}

This review article provides a comprehensive overview and analysis of current and experimental cannabidiol (CBD) delivery methods and examines the pharmacological significance of various dosage forms and delivery systems. There are a limited number of CBD-based drugs on the market, many of them utilizing conventional dosage forms, i.e., capsules, oils, creams. The objective of this review is to evaluate various CBD formulations and analyze their formulation, bioavailability, and therapeutic effectiveness. CBD formulations were classified as conventional, transdermal, emulsion, nanoparticle, and miscellaneous. It also provides an exhaustive review of all CBD formulations from research articles, patent publications, and commercial products. In addition, studies data provided by inquiries to contrast new dosage forms with those currently available, like Epidiolex, dronabinol, and various overthe-counter formulations. The expected outcome of this review article is to better inform the scientific community on advancements in delivering CBD, which may improve patient outcomes.

\section{Keywords}

Cannabidiol, drug delivery, dosage forms, CBD, cannabis, marijuana, cannabinoid, CB1, CB2

* Corresponding author: Prof. Abhay Singh Chauhan, PhD, MPharm, BPharm, Email: achauhan@mcw.edu'Tel: (414) 955-2863 


\section{Introduction}

The legal landscape of cannabis use, distribution, and pharmaceutical development is continuously changing. Recently hemp products have been legalized nationwide in the United States by the Farm Bill on December $20^{\text {th }}, 2018$, which allowed products utilizing cannabinoids (CBs) for over-the-counter purchases provided they have $<0.3 \%$ tetrahydrocannabinol (THC) by dried weight. ${ }^{1,2}$ While pharmaceuticals are regulated more closely, a shift to pharmaceuticalgrade products was inevitable. The most utilized cannabinoids in these OTC and pharmaceutical products are cannabidiol (CBD) and THC, with THC-based products only being available in some states that have approved them for medical use. These cannabinoids have a complex pharmacokinetic profile, including low bioavailability attributed to high lipophilicity, poor water solubility, and a significant firstpass effect. ${ }^{3}$ Cannabinoids impact CB1 and CB2 receptors in the endocannabinoid system, with CBD (Figure 1) affecting both receptors. ${ }^{3,4}$ CB2 receptors are thought to work by indirect agonism that either modulate receptor constitutional activates or increases endocannabinoids by inhibiting degradative enzymes. ${ }^{4}$ Another unique aspect of CBD is its ability to interact with the transient receptor potential cation channel subfamily $\mathrm{V}$ member 1 (TRPV1), which is the protein responsible for temperature and nociception control. ${ }^{5}$

CBD has complications when being formulated as well as pharmacokinetic issues. It has been observed that oral CBD undergoes an extensive first-pass hepatic metabolism. The high lipophilicity of the CBD leads to impaired absorption into the blood. ${ }^{6} \mathrm{~A}$ transdermal delivery system can help overcome this limitation by circumventing the first pass metabolism while limiting side effects. One potential benefit of this delivery system would be that the CBD's lipophilicity would allow accumulation within the stratum corneum and further permeation to deeper skin layers. ${ }^{7}$ Orally administered liquid containing CBD can be used for seizure treatments/prophylaxis, arthritis, and many other conditions. ${ }^{8}$ The addition combination therapy with corticosteroids, COX-2 inhibitors, or nonsteroidal anti-inflammatory drugs can be used for mix-type pain such as nociceptive and neuropathic pain, acute and chronic pain. ${ }^{9}$ The composition of $\mathrm{CBD}$ and inactive ingredients such as non-aqueous-based solutions, suspensions, emulsions, microemulsions, micellar solutions, gels, and ointments can treat inflammation and inflammation-related disorders and pain. ${ }^{7} \mathrm{CBD}$ also has other effects on cancer patients, such as an anti-emetic and an increase in appetite. ${ }^{10}$

It is well known that cannabinoids have poor aqueous solubility and extensive first-pass metabolism ${ }^{3}$. Often these compounds are ingested, and it has been found that there is some form of food mediated/fat dependent absorption. ${ }^{11}$ Topical formulations can be in the form of gel, cream, lotion, liquid, emulsion, ointment, spray, solution, and suspension. ${ }^{7}$ The inactive ingredients in the topical formulations included emollient, solubility enhancer, and thickening agent. ${ }^{12}$ The compositions provide synergistic results when used in topical administration to affected areas such as joints or on the skin, although the unique PK of CBD inhibits its ability to penetrate the cell membrane. ${ }^{11}$

Overall, CBD's effects on the human body are still not fully understood. ${ }^{13}$ Many studies are still being conducted to discover these unknowns and identify new ways to deliver this drug product. To date, generalized drug delivery reviews have been published that assessed drug delivery systems as various classes, such as nanoparticles, but have not evaluated all delivery systems in a class. ${ }^{14}$ This observation prompted the search and compilation of a comprehensive literature review. The search to optimize the delivery of CBD and THC with the most efficacious formulation will lead to improved PK profiles, increased benefits, and efficient product utilization. This review article discusses various drug delivery approaches to deliver cannabis and related substances.

This review article was classified into five groups to understand the role of different drug delivery systems in delivering CBD and related compounds. These groups are conventional, transdermal, emulsions, nanoparticle-based, and various dosage forms. Conventional formulations are based on generally used dosage forms such as solutions, suspensions, tablets, capsules. Emulsions are also conventional dosage forms but are used frequently to formulate lipophilic cannabinoids. Cannabinoids are lipophilic, so these phases must also be lipophilic. It may include oil, ethanol, or any organic solvent base. Topical formulations include any 
formulation designed for application on the skin, whereas transdermal is specifically used for skin penetration. These dosage forms include creams, lotions, and patches. Emulsion formulations include any formulation which employs at least a binary phase to disperse the active pharmaceutical ingredient in a water/oil mixture. Emulsion-based formulations can also employ more than one phase resulting in a colloidal dispersion. Finally, the nanoparticlebased formulation includes any formulation which utilizes nanometer-size material. The size range of nanoparticles could be up to 1000 $\mathrm{nm}$, but the FDA uses $100 \mathrm{~nm}$ as a cut-off for any nano-size material. ${ }^{15}$ Various dosage forms include any formulation which does not fit into the other categories because of their novel nature. Some of these formulations could fall within the scope of multiple categories; however, only one was selected for clarity; this chosen category also most closely resembles the function of the formulation.

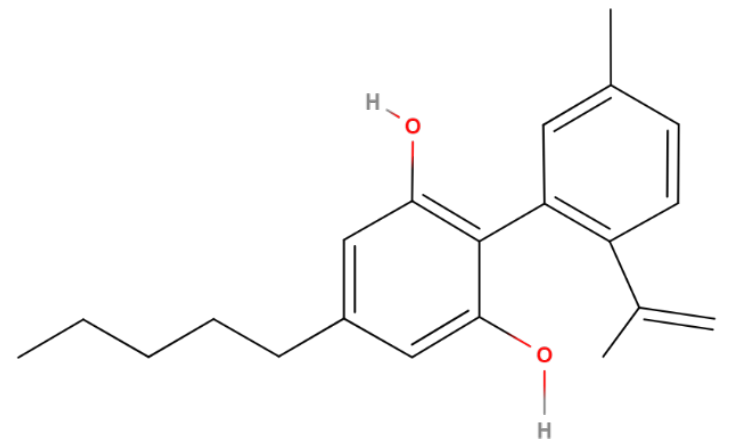

Figure 1. Chemical composition of Cannabidiol $\left(\mathrm{C}_{21} \mathrm{H}_{30} \mathrm{O}_{2}\right)$ in its non-ionized state.

\section{Materials and Methods}

\section{Eligibility Criteria}

The PICOS (Population, Interventions, Comparisons, Outcomes, Study) model was used to formulate the questions for this study: (i) studies involving cell-based models, animals, or humans; (ii) studies that describe the methodology of a drug delivery system incorporating CBD; (iii) studies that focused primarily on the delivery of CBD; (iv) studies that describe the application of the drug delivery system; and (v) preclinical (in vitro or in vivo, or in-ovo), clinical studies, or patent of the delivery system. The focus of this question was: 'What drug delivery systems are being employed to administer CBD for use in the practical setting?' Studies were included if they met the PICOS criteria set and were between January $1^{\text {st }}, 2015$, and August $31^{\text {st }}, 2021$.

Studies were excluded if i) no description of the delivery system was described, or no indication of the components used; ii) the delivery system was not primarily focused on CBD or had no CBD component analyzed, and iii) the delivery system was described in another article or patent. In addition, we excluded case reports, articles not written in English, abstracts, editorials, letters to the editor, reviews, meta-analyses, and book chapters. Studies that included the study of THC in the product formulation were only reviewed if it was a subset of the study and not the primary focus.

Our review involves a systematic search conducted on August $31^{\text {st }}, 2021$. First, a search was conducted on PubMed Clinical Queries using combinations of terms involving the terms "cannabinoid," "cannabidiol," or "CBD," combined with other terms including "delivery systems," "transdermal delivery," "emulsions," "topical preparations," "nanoparticles," and "oils." The search was manually conducted on Google Scholar with the term "CBD drug delivery patent." Articles were first accessed by title and abstract and filtered by duplicated.

\section{Results}

\subsection{Selection of studies}

The searches resulted in 458 articles on PubMed Clinical Queries and 297 articles on google scholar. The articles on Pub Med were first filtered by title, and abstract resulting in 70 articles to be accessed in full. Next, the 297 articles on Google Scholar were filtered for duplicates from the PubMed search, titles, and abstracts resulting in 26 articles to be reviewed in full. Of the 70 articles accessed on PubMed, 31 were included in the review, and of the 26 articles accessed on Google Scholar, 6 were included in this review (Figure 2). 

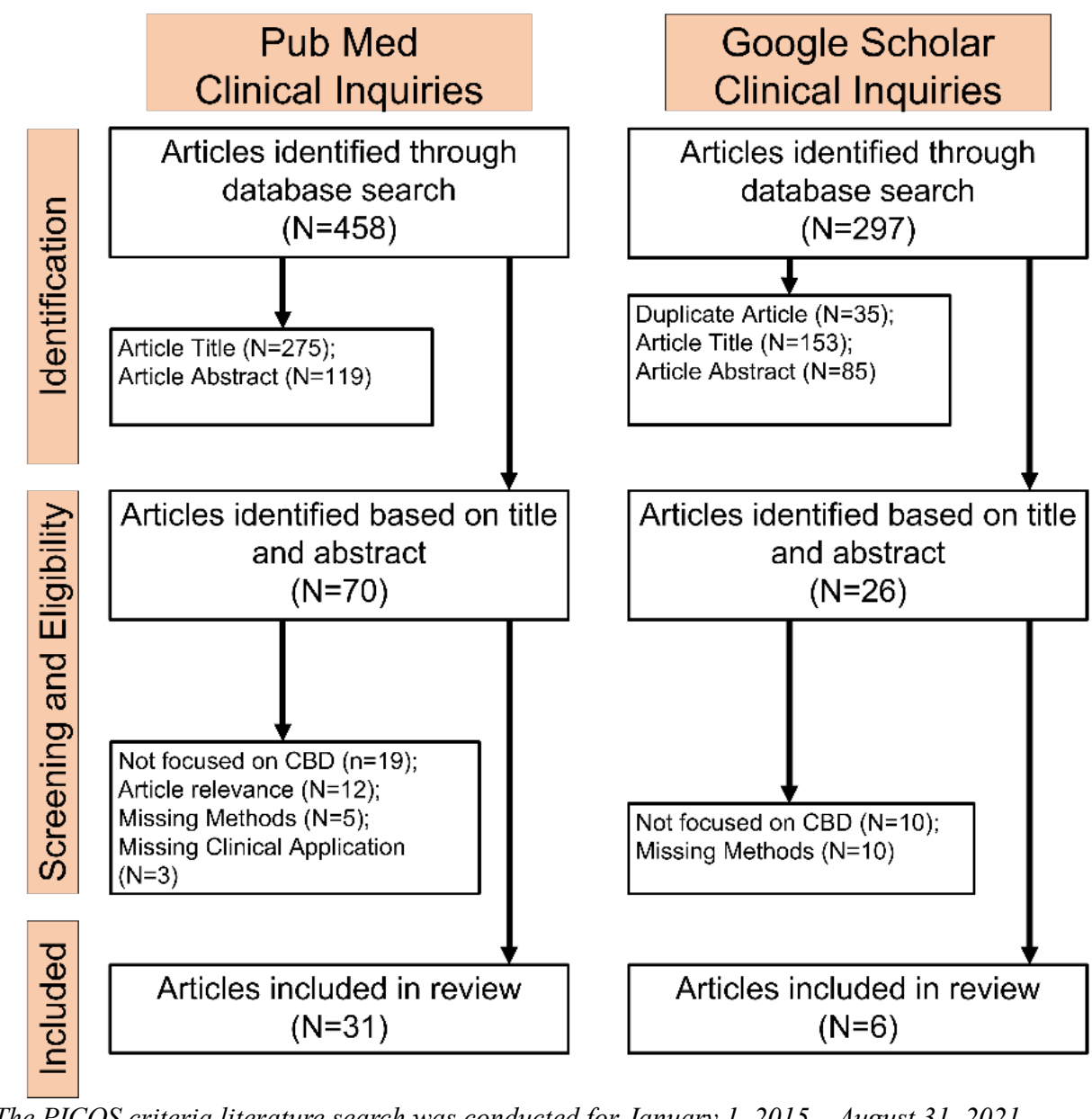

Figure 2. The PICOS criteria literature search was conducted for January 1, 2015 -August 31, 2021.

\subsection{Conventional Dosage Forms}

The most conventional method to deliver medication is an oral capsule, elixir, suspension, or solution (Table 1). CBD formulations in this classification are designed to incorporate other lipophilic components, such as oil to increase absorption. Most studies in this group analyze the systemic absorption, pharmacokinetic parameters, and their therapeutic effects.

\subsubsection{Nabiximol Oromucosal Spray ${ }^{16}$}

Allsop et al. carried out a study to compare the pharmacokinetic profiles and relative bioavailability between nabiximol and dronabinol while treating cannabis dependence. Dronabinol is an orally administered capsule of synthetic THC, whereas nabilone is a synthetic analog of both THC and CBD in an oromucosal spray. Nabilone is thought to have superior bioavailability to dronabinol and reduced cannabis withdrawal but remains untested in clinical populations. The study conducted by Allsop et al. compared dronabinol and nabilone to verify if nabilone allows for better absorption and bioavailability. Patients were treated with nabilone or dronabinol and had their cannabis dependence evaluated in the clinic after 12 weeks.

After 12 weeks, an outpatient randomized control trial treated by dronabinol showed that dronabinol did not reduce illicit cannabis use. The THC component of nabiximols provides agonist substitution to both $\mathrm{CB} 1$ and $\mathrm{CB} 2$ receptors. The CBD content of nabiximols is thought to work as an agonist on CB1 receptors. The combination of THC and CBD is rarely seen in current CBD research and is typically avoided due to having overlapping receptor targets. It is interesting to study the relationship when combined in a dosage form to see if they elicit an effect on the delivery to a patient. CB1 CBD content likely adds anxiolytic, antidepressant, and antipsychotic effects to the simple agonist THC substitution approach and facilitates the delivery of high THC doses needed to control cannabis cravings. Hence, the high levels of CBD in nabiximol can give a positive therapeutic effect and counteract the anxiety, low mood, 
cognitive deficits associated with heavy illicit cannabis use.

\subsubsection{Cannabis Sativa Oil Extract in Cap- sules $^{17}$}

Birnbaum et al. carried out a study to compare the pharmacokinetic profiles between the fed state and fasting state in patients with epilepsy using CBD oral capsules. CBD capsules were infused with CBD oil and had the pharmacokinetic parameter analyzed. Capsules were loaded with $99 \%$ purified CBD extract from
Cannabis Sativa. A linear mixed-effects analysis of variance (ANOVA) model was used to calculate the area under the curve (AUC) $)_{0-\infty}$, $\mathrm{C}_{\max }$ point estimates for the fed and fasting states. The effect of CBD on cognitive function was analyzed in two ways. First, the study compared fed and fasting states after dosing. Second, the researchers accounted for the differences in baseline performance by calculating relative change scores (postdose-predose/predose).

Table 1. Summary of articles classified under conventional dosage forms.

\begin{tabular}{|c|c|c|c|c|c|}
\hline Name & Formulation & $\begin{array}{r}\text { De- } \\
\text { livery }\end{array}$ & Study Characteristics & Results & $\begin{array}{r}\mathrm{Ci}- \\
\text { tation }\end{array}$ \\
\hline Nabiximol & $\begin{array}{l}\text { Synthetic THC an- } \\
\text { alog and CBD in } \\
\text { Sublingual Formu- } \\
\text { lation }\end{array}$ & $\begin{array}{l}\text { Oro- } \\
\text { muco- } \\
\text { sal } \\
\text { spray }\end{array}$ & $\begin{array}{l}\text { Study to compare the pharmacokinetic pro- } \\
\text { files and relative bioavailability between } \\
\text { nabiximol and dronabinol while treating } \\
\text { cannabis dependence. }\end{array}$ & $\begin{array}{l}\text { Nabiximol can give a posi- } \\
\text { tive therapeutic effect and } \\
\text { counteract the anxiety, low } \\
\text { mood, and cognitive deficits } \\
\text { associated with heavy illicit } \\
\text { cannabis use. }\end{array}$ & 16 \\
\hline $\begin{array}{l}\text { Oil Extract } \\
\text { Capsules }\end{array}$ & $\begin{array}{l}\text { Cannabis Sativa } \\
\text { Oil Extract in Cap- } \\
\text { sule }\end{array}$ & Oral & $\begin{array}{l}\text { Compare the pharmacokinetic profiles be- } \\
\text { tween the fed state and fasting state in pa- } \\
\text { tients with epilepsy using CBD oral cap- } \\
\text { sules. }\end{array}$ & $\begin{array}{l}\mathrm{C}_{\max } \text { and AUC0- } \infty \text { were } 14 \\
\text { and } 4 \text { times higher in the fed } \\
\text { state than fasting. CBD } \mathrm{T}_{\max } \\
\text { was lower in the fed state at } \\
2.4 \text { hours than } 3.2 \text { hours in } \\
\text { the fasting state. }\end{array}$ & 17 \\
\hline $\begin{array}{l}\text { Sesame Oil } \\
\text { Capsules }\end{array}$ & $\begin{array}{l}\text { Mixed Canna- } \\
\text { binoid Capsule in } \\
\text { Sesame Oil }\end{array}$ & Oral & $\begin{array}{l}\text { Safety and efficacy study of cannabinoids } \\
\text { in animals. }\end{array}$ & $\begin{array}{l}\text { No significant adverse ef- } \\
\text { fects were seen, with the } \\
\text { doses ranging from a mini- } \\
\text { mum of } 15 \text { or } 20 \mathrm{mg} / \text { day to } \\
\text { a maximum of } 1,200-1,500 \\
\mathrm{mg} / \text { day. }\end{array}$ & 18 \\
\hline Epidiolex & $\begin{array}{l}\text { Pure CBD Formu- } \\
\text { lation }\end{array}$ & Oral & $\begin{array}{l}\text { Epidiolex was studied in children with } \\
\text { Lennox-Gastaut syndrome \& Dravet } \\
\text { syndrome and was compared against pla- } \\
\text { cebo. }\end{array}$ & $\begin{array}{l}T_{\max } \text { was found to be } 2.5 \\
\text { hours, but } 5 \text { hours when } \\
\text { achieving Css. High- } \\
\text { fat/high-calorie meals } \\
\text { yielded an area under the } \\
\text { curve (AUC) } 4 \text {-fold increase. } \\
\text { The } \mathrm{T}_{1 / 2} \text { of the product was } \\
\text { seen to be } 56-61 \text { hours after } \\
\text { conducting twice daily dos- } \\
\text { ing for seven days. }\end{array}$ & 19 \\
\hline $\begin{array}{l}\text { Subcutane- } \\
\text { ous CBD } \\
\text { Ethanol }\end{array}$ & $\begin{array}{l}\text { CBD } 70 \% \text { EtOH } \\
\text { SQ Solution }\end{array}$ & $\begin{array}{l}\text { Subcu- } \\
\text { taneous }\end{array}$ & $\begin{array}{l}\text { Anxiety levels were tested at } 7,14 \text {, and } 21 \\
\text { days via an elevated plus maze, and had his- } \\
\text { topathological adipose tissue evaluated at } \\
\text { the same time intervals. }\end{array}$ & $\begin{array}{l}\text { Adipose tissue in rats treated } \\
\text { with cannabis had smaller } \\
\text { and fewer cells and lowered } \\
\text { observed anxiety in rats } \\
\text { given cannabis. }\end{array}$ & 20 \\
\hline $\begin{array}{l}\text { Soft Gel } \\
\text { Capsules }\end{array}$ & $\begin{array}{l}\text { CBD soft gels } \\
\text { containing } 15.7 \mathrm{mg} \\
\mathrm{CBD}, 0.5 \mathrm{mg} \text { THC, } \\
0.3 \mathrm{mg} \text { cannabidi- } \\
\text { varin (CBDV), } 0.9 \\
\mathrm{mg} \text { cannabidiolic } \\
\text { acid (CBDA), } 0.8 \\
\mathrm{mg} \text { cannabichrome } \\
(\mathrm{CBC}), \text { and }>1 \% \\
\text { botanical terpene } \\
\text { blend }\end{array}$ & Oral & $\begin{array}{l}\text { Patients were evaluated at baseline, } 4 \\
\text { weeks, and } 8 \text { weeks on analgesic dose re- } \\
\text { duction and pain, enjoyment, general activ- } \\
\text { ity (PEG) scores. }\end{array}$ & $\begin{array}{l}53.2 \% \text { of participants were } \\
\text { able to reduce their opioid } \\
\text { use in } 8 \text { weeks. }\end{array}$ & 21 \\
\hline
\end{tabular}

The results showed that $\mathrm{C}_{\max }$ and $\mathrm{AUC}_{0-\infty}$ were 14 times and 4 times higher, respectively, in the fed state compared to the fasting state. $\mathrm{CBD} \mathrm{T}_{\max }$ was lower in the fed state at 2.4 hours than 3.2 hours in the fasting state. Half-life was higher in the fasting state at 38.9 hours compared to the fed state at 24.3 hours. There was a significantly higher overall $\mathrm{C}_{\max }(\mathrm{p}=0.025)$ and 
$\mathrm{AUC}_{0} \infty(\mathrm{p}=0.008)$ when administering CBD with a high-fat meal). No significant period effect for $\mathrm{C}_{\max }$ and $\mathrm{AUC} 0-\infty$ was observed $(\mathrm{P}>$ $0.05)$. The study found that a patient's fed state could lead to longer gastric transit time, thus resulting in an increase in dissolution for highly lipophilic drugs, which increased absorption and bioavailability. Therefore, patients who take CBD with high-fat meals can increase solubility, improve intestinal absorption, and enhance the absorption of CBD to the lymphatic system.

\subsubsection{Mixed Cannabinoid Capsules in Ses- ame Oill ${ }^{18}$}

Online surveys have been used to identify the use of cannabis products in pets. These online surveys have shown that an increasing amount of pet owners have used cannabis products for their pets for pain, inflammation, and anxiety. Because of this, Vaughn et al. researched the safety and efficacy of cannabinoids in animals. The primary objective of this study was to determine the safety of three cannabis oil formulations containing either CBD, THC, or a combination of the two. This formulation was produced as an oral gelatin capsule filled with CBD and THC oils and tested against a placebo sunflower seed oil. The second objective of this study was to determine the blood levels of CBD, THC, and metabolites. The prime metabolites investigated were 7-carboxy-CBD (7$\mathrm{COOH}-\mathrm{CBD})$ and 11-hydroxy-THC (11-OHTHC) at high doses of CBD $(>50 \mathrm{mg} / \mathrm{kg})$ and THC $(>30 \mathrm{mg} / \mathrm{kg})$. Capsules with CBD and THC were filled with a CBD: THC ratio of 1.5:1.

The results found no significant adverse effects, with the doses ranging from a minimum of 15 or $20 \mathrm{mg} / \mathrm{day}$ to a maximum of 1,200 $1,500 \mathrm{mg} /$ day. There were mild side effects, such as gastrointestinal, constitutional, or neurological symptoms. The oral doses of CBD in dogs showed that doses of $2-2.5 \mathrm{mg} / \mathrm{kg}$ twice daily for $4-12$ weeks and $5-10 \mathrm{mg} / \mathrm{kg}$ twice daily for 6 weeks were well tolerated. The results showed that $\mathrm{CBD}$-predominant oil formulations in combination with THC had the highest tolerability in dogs at a maximum dose of $640.5 \mathrm{mg} \mathrm{CBD}(\sim 62 \mathrm{mg} \mathrm{CBD} / \mathrm{kg})$.

\subsubsection{Epidiolex $^{19}$}

Epidiolex is currently the only FDA-approved pure CBD formulated product. Epidiolex has the labeled indication to prevent specific types of seizures, specifically Lennox-Gastaut syndrome (LGS) and Dravet syndrome (DS). This formulated product is supplied as $100 \mathrm{mg} / \mathrm{mL}$ clear solution of pure CBD. The dosing of this medication was studied and had an initial dose of $2.5 \mathrm{mg} / \mathrm{kg}$ twice daily and can be titrated to a maximum daily dose of $10 \mathrm{mg} / \mathrm{kg}$ twice daily. Various studies were conducted to evaluate this product's safety profile and pharmacokinetics. Epidiolex was studied in children with LGS \& DS and was compared against placebo.

The $\mathrm{T}_{\max }$ was found to be 2.5 hours, but 5 hours when achieving $\mathrm{C}_{\mathrm{ss}}$. When administering with a high-fat/high-calorie meal, the AUC would have a 4-fold increase. The $\mathrm{T}_{1 / 2}$ of the product was seen to be $\sim 56-61$ hours after conducting twice-daily dosing for seven days. The $\mathrm{V}_{\mathrm{D}}$ was found to be $1111 \mathrm{~L} / \mathrm{H}$.

\subsubsection{Cannabis Sativa Extract in Ethano ${ }^{20}$}

Kamali et al. studied the effects of CBD in rats' behavior and absorption when given as an ethanol extract. C. Sativa powder was dried and crushed into powder with a particle size $<4.5$ $\mathrm{cm}$. The powder was macerated and combined in $70 \%$ ethanol for $2-4$ days. The solution was shaken twice daily to allow for homogeneity. The product was filtered and had the solute solution undergo rotary evaporation followed by oven drying at $40^{\circ} \mathrm{C}$. The dried extract was dissolved in $70 \%$ ethanol to the desired concentrations. The rats had subcutaneous injections of 2 $\mathrm{mg} / \mathrm{kg}$ daily for 3 weeks compared to rats receiving only $70 \%$ ethanol.

Anxiety levels were tested at 7, 14, and 21 days via an elevated plus maze and had histopathological adipose tissue evaluated simultaneously. After the cannabis was administered, there was a distinct change in the adipose tissue's inflammation, degradation, and necrosis. The adipose tissue in rats treated with cannabis had smaller and fewer cells. Behavioral assessments showed no significant changes in the first week but did have changes in weeks 2 and 3. It was found that there was a significant difference in anxiety in rats given cannabis $(p<$ 0.001 ) based on the percent time spent in the central parts of the maze.

\subsubsection{Mixed Cannabinoids in Soft Gel Cap- sules $^{21}$}

Capano et al. studied the impact of CBD as a potential alternative to pain and opioid therapy. 
Participants were recruited to receive treatment with CBD soft gels containing $15.7 \mathrm{mg}$ CBD, $0.5 \mathrm{mg}$ THC, $0.3 \mathrm{mg}$ cannabidivarin (CBDV), $0.9 \mathrm{mg}$ cannabidiol acid (CBDA), $0.8 \mathrm{mg}$ cannabichromene $(\mathrm{CBC})$, and $>1 \%$ botanical terpene blend. CBD soft gel capsules are made by extracting the contents of hemp and are surrounded by a gelatin-based shell. Patients were evaluated at baseline, 4 weeks, and 8 weeks on analgesic dose reduction and pain, enjoyment, general activity (PEG) scores. Results showed that $53.2 \%$ of participants could reduce their opioid use in 8 weeks. PEG scores showed a significant reduction $(\mathrm{p}=0.006)$ from baseline PEG scores by 6.5 [95\% CI 6.16-6.81].

\subsection{Topical/Transdermal Dosage Forms}

Transdermal formulations are typically used for pain/discomfort, arthritis, neuralgia and can circumvent the body's first-pass effect, preventing systemic absorption. Topical formulations of CBD were developed to assist with localized pain and nervous system-related conditions. Most articles under this class could fall under other classifications, such as nanoparticles, emulsions, oils, but were better suited to discuss here (Table 2). Most of the articles in question were patents for potential delivery methods.

\subsubsection{Extract in Olive Oil22}

Nitecka-Buchta et al. evaluated the application of a transdermal CBD in an olive oil vehicle to help with pain control after dental procedures. In a randomized control trial, clinicians created $20 \%$ CBD oil formulations to be tested against a placebo to determine its effectiveness in treating myofascial pain. The $20 \%$ oil extract was obtained from Charlotte's Web Hemp Oil Extract, which was prepared in olive oil as the vehicle. The extract was tested and deemed to contain $1.46 \%$ CBD. A cholesterol ointment was used as the drug delivery medium due to its ability to be an absorbent medium, as well as an emulsifying vehicle. The product included oleum CBD and aqua purificata to form the transdermal product. The result produced a formulation that was consistent with that of an ointment.

Nitecka-Buchta et al. split 60 individuals into treatment and control arms. The participants had a masseter muscle activity test and a surface electromyography test conducted on days 0 and 14. The patients were to apply the formulation twice daily for the 14 days of the trial. The activity of the masseter muscles showed a decrease of $\sim 12 \%$ for each muscle in the treatment group and $0.23-3.3 \%$ in the control group. A visual pain scale was done for each group and showed a reduction of $70.2 \%$ in the treatment group and $9.81 \%$ in the control group. The muscle activity of the masseter muscles was shown to be reduced when given the CBD formulation, resulting in lower overall pain.

\subsubsection{Extract in Propylene Glycol and Dense Cream $^{23}$}

Giacoppo et al. studied the therapeutic effects of a formulated CBD cream on mice with experimental autoimmune encephalomyelitis (EAM), a standard model used to model multiple sclerosis (MS). The study was conducted to find an alternative, non-invasive way to treat MS and limb recovery patients. The formulation was made by taking pure CBD ( $>98 \%$ purified) and solubilizing it in propylene glycol and dense cream resulting in a $1 \%$ CBD formulation. This $\mathrm{O} / \mathrm{W}$ was used to combat the hydrophobic properties possessed by CBD. CBD cream was placed in a $1 \mathrm{~cm}^{2}$ area daily after EAM was introduced. Mice were split into 2 arms that tested the effects with the 1\% CBD cream compared to the vehicle alone. Blood tests were then performed to evaluate systemic levels. Western blotting was done on various biomarkers. $\mathrm{C}_{\max }$ was found to be $8.3 \pm 2.1$ $\mathrm{ng} / \mathrm{mL}$, with a $\mathrm{T}_{1 / 2}$ of $38.2 \pm 18.9$ hours and a $\mathrm{C}_{\mathrm{SS}}$ of $6.1 \pm 1.9 \mathrm{ng} / \mathrm{mL}$. Mice with the CBD treatment had a significant reduction $(p \leq 0.05)$ of IL- $1 \beta$, IL- 6 , TNF- $\alpha$, TGF- $\beta$, and INF- $\gamma$ levels in the spinal cord compared to the control. It was determined that the topical formulation could influence the secretion of pro-inflammatory cytokines. It was seen that the formulation reduced oxidative injury caused by nitrotyrosine, INOS, and PARP. One of the significant effects observed was that cleaved-caspase-3, an enzyme involved in programmed cell death, levels were decreased. This means that CBD could help prevent cell death of various necrosis-related diseases. 
Table 2. Summary of articles classified under topical/transdermal dosage forms.

\begin{tabular}{|c|c|c|c|c|c|}
\hline Name & Formulation & Delivery & Study Characteristics & Results & Citation \\
\hline $\begin{array}{ll}\text { Olive } & \text { Oil } \\
\text { Extract } & \end{array}$ & Transdermal & $\begin{array}{l}\text { CBD Olive } \\
\text { Oil Formu- } \\
\text { lation }\end{array}$ & Topical & $\begin{array}{l}\text { In a randomized control } \\
\text { trial, clinicians created } \\
20 \% \mathrm{CBD} \text { oil formula- } \\
\text { tions to be tested } \\
\text { against a placebo to de- } \\
\text { termine its effective- } \\
\text { ness in treating myo- } \\
\text { fascial pain. }\end{array}$ & 22 \\
\hline $\begin{array}{l}\text { Propylene } \\
\text { Glycol and } \\
\text { Dense } \\
\text { Cream with } \\
\text { Extract }\end{array}$ & $\begin{array}{c}\text { CBD Propylene Glycol and } \\
\text { Dense Cream }\end{array}$ & Topical & $\begin{array}{l}\text { The study was conducted to find } \\
\text { an alternative, non-invasive way } \\
\text { to treat patients with MS and } \\
\text { limb recovery in a mouse model. }\end{array}$ & $\begin{array}{l}\mathrm{C}_{\max } \text { was found to be } \\
8.3 \pm 2.1 \mathrm{ng} / \mathrm{mL} \text {, with a } \\
\mathrm{T}_{1 / 2} \text { of } 38.2 \pm 18.9 \\
\text { hours and a } \mathrm{C}_{\mathrm{Ss}} \text { of } 6.1 \pm \\
1.9 \mathrm{ng} / \mathrm{mL} \text {. }\end{array}$ & 23 \\
\hline $\begin{array}{l}\text { Ethosomal } \\
\text { Carrier }\end{array}$ & $\begin{array}{l}\text { CBD-loaded Ethosomal Car- } \\
\text { rier }\end{array}$ & Topical & $\begin{array}{l}\text { CBD ethosomal carriers were } \\
\text { studied to determine if the for- } \\
\text { mulation could improve dermal } \\
\text { and transdermal delivery }\end{array}$ & $\begin{array}{l}\text { Ethosomal carriers effi- } \\
\text { ciently delivered CBD } \\
\text { to the inflamed area } \\
\text { and would cause a ther- } \\
\text { apeutic effect at the } \\
\text { site. }\end{array}$ & 24 \\
\hline $\begin{array}{l}\text { Extract in } \\
\text { Monohydric } \\
\text { Alcohol }\end{array}$ & $\begin{array}{l}\text { Mixed Cannabinoid Mono- } \\
\text { hydric Alcohol Solution in } \\
\text { Capsules }\end{array}$ & Topical & $\begin{array}{l}\text { The method of creating a topical } \\
\text { CBD analgesic was patented us- } \\
\text { ing a } 70 \% \text { monohydric alcohol } \\
\text { solution to form a liniment prod- } \\
\text { uct when combined with } 0.5- \\
2.5 \% \text { cannabis mixture extract. }\end{array}$ & $\mathrm{N} / \mathrm{A}$ & 25 \\
\hline $\begin{array}{l}\text { Emu Oil } \\
\text { and Cam- } \\
\text { phor Tinc- } \\
\text { ture }\end{array}$ & $\begin{array}{c}\text { CBD Emu Oil and Camphor } \\
\text { Tincture }\end{array}$ & Topical & $\begin{array}{l}\text { The formulation combines CBD } \\
\text { with Emu oil, eucalyptus oil, and } \\
\text { camphor to overcome the lipo- } \\
\text { philicity concerns of CBD. }\end{array}$ & N/A & 26 \\
\hline $\begin{array}{l}\text { Microneedle } \\
\text { Hydrogel }\end{array}$ & $\begin{array}{l}\text { Cannabinoid Prodrugs via } \\
\text { Microneedle Apparatus }\end{array}$ & Topical & $\begin{array}{l}\text { Transdermal administration of } \\
\text { cannabinoid prodrugs with a mi- } \\
\text { croneedle apparatus is described } \\
\text { in a patent for use in treating al- } \\
\text { cohol use disorder, pain, inflam- } \\
\text { mation, and pancreatic diseases. }\end{array}$ & N/A & 27 \\
\hline $\begin{array}{l}\text { Smart Mi- } \\
\text { crogel }\end{array}$ & $\begin{array}{l}\text { Thermoresponsive of poly- } \\
\text { (ethylacrylate-co- } \\
\text { methylacrylate-co-trime- } \\
\text { thylammo-nioethylmethac- } \\
\text { rylate chloride) Microneedle } \\
\text { Patch }\end{array}$ & Topical & $\begin{array}{l}\text { Evaluating the loading capabili- } \\
\text { ties of CBD in holt melted trans- } \\
\text { dermal patches with acrylate- } \\
\text { based polymers. }\end{array}$ & $\begin{array}{l}\text { The optimal melting } \\
\text { temperature of } 39^{\circ} \mathrm{C} \text {. } \\
\text { Average particle cross- } \\
\text { sectional length of } 100 \\
\mathrm{~nm} \text {. }\end{array}$ & 28,29 \\
\hline
\end{tabular}

\subsubsection{Ethosomal Carriers $^{24}$}

CBD is believed to assist in the treatment of rheumatic diseases (RD) due to its anti-inflammatory effects. CBD ethosomal carriers were studied by Lodzki et al. to determine if the formulation could improve dermal and transdermal delivery. The CBD ethosomal carriers were characterized by transmission electron microscopy containing 3\% w/w CBD and $40 \% \mathrm{w} / \mathrm{w}$ $\mathrm{EtOH}$ in a carbomer gel. Two different qualitative systems were used to see any effect on the carriers at high temperatures. This was done to ensure human body temperature would not destroy the carrier.

Confocal laser scanning microscopy and differential scanning calorimetry showed no effect on the carriers, allowing for proper drugs re- lease. Throughout the study, the authors concluded that the ethosomal carriers efficiently delivered CBD to the inflamed area and would cause a therapeutic effect at the site.

\subsubsection{Mixed Cannabinoid Extract in Mono- hydric Alcohol ${ }^{25}$}

A method of creating a topical (CBD) analgesic was patented by using a $70 \%$ monohydric alcohol solution to form a liniment product when combined with $0.5-2.5 \%$ cannabis mixture extract. THC, THC-V, CBD, CBD-V, $\mathrm{CBN}, \mathrm{CBC}, \mathrm{CBC}-\mathrm{V}, \mathrm{CBG}$, terpenoids, and flavonoids. The product was designed to be applied to the skin via a spray that would then allow the solution to be absorbed through the skin. It was thought that the solution would interact with cannabinoid receptors to produce an 
analgesic and anti-inflammatory effect while limiting side effects.

The product was made by soaking and seeping the Cannabis Stevia plant in the alcohol product until it contained $0.9-2.5 \%$ of the cannabinoid extract. It was found that the preferred weight of the extract was $1.3 \%$. Wallace also saw that the process could be sped up with a temperature increase to $85-115^{\circ} \mathrm{F}$ for $50-70$ hours. They stated that a recommended dose of $2 \mathrm{oz}$. should be applied topically for seven days to have a full effect. No data has been reported on this formulation to support these claims.

\subsubsection{Emu Oil and Camphor Tincture ${ }^{26}$}

Emu oil is an oil tincture comprised of myristic acid, palmitic acid, palmitoleic acid, margaric acid, stearic acid, elaidic acid, ole vaccenic acid, linoleic acid, linolenic acid, arachidic acid, and eicosenoic acid. Highly lipophilic mediums like emu oil dissolve lipophilic mediations allowing for dissolution and has been patented due to this rationale. The suggested formulation combines CBD with emu oil, eucalyptus oil, and camphor to overcome the lipophilicity concerns of CBD. In addition, the emu oil allows for transdermal transport into the hypodermis, where CBD can then be released. However, no data has been reported on this formulation to support these claims.

\subsubsection{Microneedle Administered Hydroge ${ }^{27}$}

Topical and transdermal administration of cannabinoid prodrugs with a microneedle apparatus is described in a patent for use in treating alcohol use disorder, pain, inflammation, and pancreatic diseases. It is thought that cannabinoids can be dispersed in either a gel or hydrogel then applied to the skin prior to the application of a microneedle apparatus. It is thought that an applicator such as this could be used in the treatment of cannabis use disorders, dystonia, chronic inflammation disorders, rheumatoid arthritis, inflammatory bowel disease, multiple sclerosis, and lupus. No data has been reported on this formulation to support these claims.

\subsubsection{Smart Microge ${ }^{28,29}$}

The formulation of a thermoresponsive microgel cannabinoid transdermal patch was conducted by Dirksen et al. using temperature-controlled drug entrapment. In short, transdermal patches are generated through hot-melting printing to generate a pressure-sensitive adhesive. This adhesive was made by creating two mixtures of poly-(ethylacrylate-co-methylacrylate-co-trimethylammo-nioethylmethacrylate chloride) at molar ratios of 1:2:0.2 and 1:2:0.1. The mixtures were melted and printed at $90^{\circ} \mathrm{C}$ through $0.7 \mathrm{~mm}$ needles. The adhesive microgels exhibit a hydrophilic interior to produce partial solubility of CBD when loaded in the heat press process. The study then analyzed the ability of CBD to be loaded in the patches.

Atomic force microscopy was performed on patches after they were dried. It was observed that the microgel particles formed circular cross-sections that averaged $100 \mathrm{~nm}$ long. The patches were then exposed to heat escalation to determine the optimal phase transition of CBD. It was seen that the optimal temperature for max phase transition was at $39^{\circ} \mathrm{C}$.

\subsection{Emulsion Based Dosage Forms}

One conventional method to overcome a lipophilic compound is to form an emulsion. CBD emulsion would allow for intestinal absorption due to the hydrophilic component from the surfactant used. The studies under this category primarily focus on the bioavailability of the CBD more than the overall effect it has (Table 3)

\subsubsection{VESIsorb Self-Emulsifying Drug Deliv- ery System ${ }^{30}$}

It has been found that food intake increases AUC and $\left(\mathrm{C}_{\max }\right)$ of CBD; however, this timedelayed effect increases $T_{\max }$. Knaub et al., 2019 , reviewed the use of a patented self-emulsifying drug-delivery system (SEDDS) for CBD by measuring and comparing plasma concentrations over time of both a SEDDS and a medium-chain triglyceride (MCT)-CBD formulation. SEDDS are mixtures of oils, surfactants, and hydrophilic solvents. These mixtures spontaneously emulsify when presented with an aqueous phase like gastric or intestinal fluids.

This emulsification allows the active lipophilic drug to pass through the human body's lumens when they typically cannot. It was found that SEDDS improves the oral bioavailability of CBD compared to the MCT formulation in healthy subjects. The $\mathrm{AUC}_{0-8 \mathrm{shs}}$ for SEDDS was $27.15 \mathrm{ng} / \mathrm{mL}^{*} \mathrm{hr}$, and 9.51 $\mathrm{ng} / \mathrm{mL}^{*} \mathrm{hr}$ for the MCT formulation; the $\mathrm{AUC}_{0 \text { - }}$ 24hrs was found to be 32.63 and $19.23 \mathrm{ng} / \mathrm{mL}^{*} \mathrm{hr}$, respectively. 
Table 3. Summary of articles classified under emulsion dosage forms.

\begin{tabular}{|c|c|c|c|c|c|}
\hline Name & Formulation & $\begin{array}{r}\text { De- } \\
\text { livery }\end{array}$ & Study Characteristics & Results & $\begin{array}{c}\text { Ci- } \\
\text { tation }\end{array}$ \\
\hline VESIsorb & $\begin{array}{l}\text { Self-Emulsifying } \\
\text { Drug Delivery System }\end{array}$ & Oral & $\begin{array}{l}\text { Patented self-emulsifying drug-delivery system } \\
\text { (SEDDS) for CBD by measuring and compar- } \\
\text { ing plasma concentrations over time of both a } \\
\text { SEDDS and a medium-chain triglyceride } \\
\text { (MCT)-CBD formulation. }\end{array}$ & $\begin{array}{l}\text { Average } \mathrm{C}_{\max } \text { meas- } \\
\text { ured at } 13.53 \mathrm{ng} / \mathrm{mL} \\
\text { for SEDDS, and } 3.05 \\
\mathrm{ng} / \mathrm{mL} \text { for MCT for- } \\
\text { mulations. }\end{array}$ & 30 \\
\hline $\begin{array}{l}\text { Nanoemul- } \\
\text { sion }\end{array}$ & $\begin{array}{l}\text { Oil-in-Water } \\
\text { Nanoemulsion Formu- } \\
\text { lation (particles w/ } \\
\text { sizes of } 50 \mathrm{~nm} \text { or less) }\end{array}$ & Oral & $\begin{array}{l}\text { Investigate the difference in absorption for ses- } \\
\text { ame oil or MIGLYOL } 812 \mathrm{~N} \text { (Type I } \\
\text { LCT/MCT SNEDDS) and cocoa butter or tri- } \\
\text { caprin (Type II LCT/MCT SNEDDS) formula- } \\
\text { tions. }\end{array}$ & $\begin{array}{l}\text { Roughly a twofold in- } \\
\text { crease for both } C_{\max } \\
\text { and AUC. }\end{array}$ & 31 \\
\hline $\begin{array}{l}\text { Silicone and } \\
\text { Hyaluronic } \\
\text { Acid }\end{array}$ & $\begin{array}{l}\text { CBD loaded Hyalu- } \\
\text { ronic acid (HLA) and } \\
\text { Silicone Emulsion }\end{array}$ & $\begin{array}{l}\text { Topi- } \\
\text { cal }\end{array}$ & $\begin{array}{l}\text { The patented process incorporated various } \\
\text { HLA and silicone polymers. }\end{array}$ & N/A & 32 \\
\hline $\begin{array}{l}\text { Boswellic Ac- } \\
\text { ids }\end{array}$ & $\begin{array}{l}\text { CBD loaded Boswel- } \\
\text { lic Acid Emulsion }\end{array}$ & Oral & $\begin{array}{l}\text { Boswellic acids have a molecular structure that } \\
\text { resembles cholesterol and is thought to interact } \\
\text { in emulsion formulations similar to bile salts, } \\
\text { allowing for CBD to be delivered. }\end{array}$ & N/A & 33 \\
\hline
\end{tabular}

An AUC difference with SEDDS is roughly three times as effective at $0-8$ hours and nearly twice as effective at 0-24 hours. Likewise, the average $\mathrm{C}_{\max }$ measured at $13.53 \mathrm{ng} / \mathrm{mL}$ for SEDDS and $3.05 \mathrm{ng} / \mathrm{mL}$ for MCT formulations. These findings indicate SEDDS will provide higher plasma concentrations with CBD. Finally, $\mathrm{T}_{\max }$ was found to be one hour for SEDDS and three hours on average for the MCT formulation. This indicates that SEDDS formulations provide a larger $\mathrm{C}_{\max }$ and can be achieved faster.

\subsubsection{Nanoemulsion ${ }^{31}$}

Izgelov et al. investigated lipid self-emulsifying drug delivery systems for $\mathrm{CBD}$ and THC/CBD formulations. Lipid solutions can easily be mechanically emulsified; however, self-nano-emulsifying systems would maintain their intended structures. Therefore, the target formulation was an oil-in-water nanoemulsion with particles sizes of $50 \mathrm{~nm}$ or less, and to investigate the difference in absorption for sesame oil or MIGLYOL ${ }^{\circledR}$ 812N (Type I LCT/MCT SNEDDS) and cocoa butter or tricaprin (Type II LCT/MCT SNEDDS) formulations. This investigation highlighted the need for further in vivo studies on cannabinoid formulations. It was reported that the LCT favoring formulations presented at roughly a 2-fold increase for both $\mathrm{C}_{\max }$ and AUC. Between the cocoa butter and sesame formulations, it was found that cocoa butter has a delayed onset compared to sesame oil. It is thought that this has to do with differences in lymphatic absorption being slower than systemic absorption kinetics. The study found that the complex nature of lipid metabolism added unpredictability to the kinetics of the formulation.

\subsubsection{Silicone and Hyaluronic Acid ${ }^{32}$}

Jackson et al. patented a topical formulated product containing hyaluronic acid (HLA) and silicone to assist wound management.

The method was designed using heat cycling combining cannabinoids, flaxseed oil, and an emulsifier to form an extract - the process allowed for the incorporation of various HLA and silicone polymers. In addition, the process allows for the application of various formulations to HLA or silicone. Various types of emulsifiers were chosen, but no specific agent was preferred. It was noted that more than one emulsifier could be used, but a hydrophilic/lipophilic balance needed to be maintained. Therefore, no pharmacokinetic studies or tests have been conducted on these products.

\subsubsection{Boswellic Acids ${ }^{33}$}

Skalicky, et al. published a patent for the generation of a boswellic acid and CBD formulation to treat inflammatory diseases. Boswellic acids have a molecular structure that resembles cholesterol and is thought to interact in emulsion formulations similar to bile salts, allowing for CBD to be delivered Boswellic acids are extracted from Boswellia Serrata and Boswellia Sancta, commonly known as frankincense. 
Table 4. Summary of articles classified under nanoparticle dosage forms.

\begin{tabular}{|c|c|c|c|c|c|}
\hline Name & Formulation & $\begin{array}{l}\text { Deliv- } \\
\text { ery }\end{array}$ & Study Characteristics & Results & $\begin{array}{l}\text { Ci- } \\
\text { tation }\end{array}$ \\
\hline $\begin{array}{l}\text { Poly (lactic- } \\
\text { co-glycolic } \\
\text { acid) Micro- } \\
\text { particles }\end{array}$ & $\begin{array}{l}\text { CBD loaded PLGA Micro- } \\
\text { particles }\end{array}$ & Oral & $\begin{array}{l}\text { CBD-loaded microparticles were } \\
\text { used in conjunction with paclitaxel } \\
\text { (PTX) and doxorubicin (DOX) } \\
\text { chemotherapy to treat breast cancer. }\end{array}$ & $\begin{array}{l}\text { CBD-loaded microparticles extended } \\
\text { the breast cancer cell's anti-prolifera- } \\
\text { tive activity for at least } 10 \text { days as a } \\
\text { monotherapy and in combination } \\
\text { with PTX or DOX. }\end{array}$ & 34 \\
\hline $\begin{array}{l}\text { Gold Nano- } \\
\text { particle } \\
\text { Complex }\end{array}$ & $\begin{array}{l}\text { CBD-loaded Gold Nano- } \\
\text { particle (AuNP) Complex }\end{array}$ & Oral & $\begin{array}{l}\text { Gold nanoparticle (AuNP) complex } \\
\text { with CBD to be infused and enhance } \\
\text { breast cancer treatment. }\end{array}$ & $\begin{array}{l}\text { Results showed a reduction of the tu- } \\
\text { mor size along with tumor removal. }\end{array}$ & 35 \\
\hline $\begin{array}{l}\text { Poly- } \varepsilon-\mathrm{Ca}- \\
\text { prolactone } \\
\text { Micro- } \\
\text { spheres }\end{array}$ & $\begin{array}{l}\text { CBD-loaded Poly- } \varepsilon \text {-capro- } \\
\text { lactone (PCL) Micro- } \\
\text { spheres }\end{array}$ & Oral & $\begin{array}{l}\text { In vitro study with PCL micro- } \\
\text { spheres to determine the efficacy of } \\
\text { the CBD release and the ideal } \\
\text { drug/polymer ratio. }\end{array}$ & $\begin{array}{l}\text { CBD-infused microparticles dis- } \\
\text { played inhibition of cell growth. Days } \\
4 \text { and } 7 \text { showed large levels of CBD } \\
\text { released but then slowed after day } 7 .\end{array}$ & 36 \\
\hline $\begin{array}{l}\text { PTL101 Oro- } \\
\text { mucosal } \\
\text { Spray }\end{array}$ & $\begin{array}{l}\text { CBD-loaded Oral Gelatin } \\
\text { Pellet Matrix }\end{array}$ & $\begin{array}{l}\text { Oro-mu- } \\
\text { cosal } \\
\text { spray }\end{array}$ & $\begin{array}{l}\text { Pharmacokinetic profile and bioa- } \\
\text { vailability study of CBD and THC } \\
\text { through an oromucosal spray. }\end{array}$ & $\begin{array}{l}10 \mathrm{mg} \text { dose of CBD in the PTL101 } \\
\text { was found to have a } 134 \%(90 \% \mathrm{CI} \text {, } \\
113 \%-59 \%) \text { increase in bioavailabil- } \\
\text { ity than the same dose of the oro- } \\
\text { mucosal spray. }\end{array}$ & 37 \\
\hline PLT401 & $\begin{array}{l}\text { CBD-loaded Oral Gelatin } \\
\text { Pellet Matrix }\end{array}$ & Oral & $\begin{array}{l}\text { Pharmacokinetic profile of the } \\
\text { PTL } 401 \text { compared to traditional for- } \\
\text { mulations. }\end{array}$ & $\begin{array}{l}\text { PTL } 401 \text { formulations had } \mathrm{T}_{\max } \text { values } \\
\text { at half of traditional CBD formula- } \\
\text { tions. }\end{array}$ & 38 \\
\hline $\begin{array}{l}\text { Poly (lactic- } \\
\text { co-glycolic } \\
\text { acid) based } \\
\text { Nanoparti- } \\
\text { cles }\end{array}$ & $\begin{array}{l}\text { CBD-loaded Poly } \\
\text { (D,L-lactide-co-glycolide) } \\
\text { Nanoparticles (PLGA NPs) }\end{array}$ & Oral & $\begin{array}{l}\text { A total of } 40 \text { mice were used to al- } \\
\text { low } 10 \text { mice to be tested for each of } \\
\text { the four different PLGA NPs. }\end{array}$ & $\begin{array}{l}\text { PEG-PLGA NPs had a } 2.2 \text {-fold re- } \\
\text { duction in tumor volume on day } 32 \\
\text { compared to the control group. On } \\
\text { day } 41 \text { a } 1.5 \text {-fold decrease was ob- } \\
\text { served. }\end{array}$ & 39 \\
\hline $\begin{array}{l}\text { Pro Nano } \\
\text { Lipospheres }\end{array}$ & CBD-loaded Lipospheres & Oral & $\begin{array}{l}\text { A nanoliposphere formulation de- } \\
\text { signed for enhanced oral absorption } \\
\text { in rats compared to standard formu- } \\
\text { lations. }\end{array}$ & $\begin{array}{l}\text { Bioavailability showed a } 2 \text {-fold in- } \\
\text { crease in the CBD-piperine-PNL for- } \\
\text { mulation compared to the CBD solu- } \\
\text { tion. }\end{array}$ & 40 \\
\hline $\begin{array}{l}\text { Piperine-pro- } \\
\text { NanoLipo- } \\
\text { spheres }\end{array}$ & $\begin{array}{l}\text { CBD-loaded Lipospheres } \\
\text { with Piperine }\end{array}$ & Oral & $\begin{array}{l}\text { Comparative study of } \mathrm{C}_{\max } \text { and } \\
\text { AUC for each respective formula- } \\
\text { tion, oral versus SL. }\end{array}$ & $\begin{array}{l}\text { 3-fold increase in } \mathrm{C}_{\max } \text { and a } 1.5 \text {-fold } \\
\text { increase in AUC compared to Sativex } \\
\text { (a buccal formulation). }\end{array}$ & 41 \\
\hline $\begin{array}{l}\text { Nanoliipid } \\
\text { Carriers }\end{array}$ & $\begin{array}{l}\text { CBD-loaded Nanolipid car- } \\
\text { rier }\end{array}$ & Oral & $\begin{array}{l}\text { Study to compare loading capacity } \\
\text { of nanolipid carrier formulations. }\end{array}$ & $\begin{array}{l}\text { Rimonabant formulations were found } \\
\text { to have a } 10 \text {-fold increase in loading } \\
\text { at } 40.00 \mu \mathrm{g} / \mathrm{mg}\end{array}$ & 42 \\
\hline $\begin{array}{l}\text { Calcium Al- } \\
\text { ginate Lipo- } \\
\text { somal Sus- } \\
\text { pension }\end{array}$ & $\begin{array}{l}\text { CBD-loaded Cross-Linked } \\
\text { Nanogel }\end{array}$ & Oral & $\begin{array}{l}\text { Patent pending detailing the encap- } \\
\text { sulation of liposomal suspensions } \\
\text { with calcium alginate. }\end{array}$ & N/A & 43 \\
\hline $\begin{array}{l}\text { Electrospun } \\
\text { fibers }\end{array}$ & $\begin{array}{l}\text { CBD-entrapped Polyvi- } \\
\text { nyl(pyrrolidone) \& Eu- } \\
\text { dragit L-100 Electrospun } \\
\text { Fibers }\end{array}$ & Oral & $\begin{array}{l}\text { Comparison of drug entrapment ca- } \\
\text { pabilities of polyvinyl(pyrrolidone) } \\
\text { and Eudragit L- } 100 \text { electrospun fi- } \\
\text { bers. }\end{array}$ & $\begin{array}{l}\text { Polyvinyl(pyrrolidone) fiber diame- } \\
\text { ter of } 700-900 \mathrm{~nm} \text {, Eudragit L-100 fi- } \\
\text { ber diameter of } 1-5 \mu \mathrm{m} \text {. Drug entrap- } \\
\text { ment of } \sim 90 \% \text {. }\end{array}$ & 44 \\
\hline $\begin{array}{l}\text { Nasal Buccal } \\
\text { Silica }\end{array}$ & $\begin{array}{l}\text { CBD Entrapment in Silica } \\
\text { Gel }\end{array}$ & Buccal & $\begin{array}{l}\text { Evaluation of Aeroperl } 300 \text { silica } \\
\text { CBD release on porcine buccal } \\
\text { cells. Evaluation of hypromellose, } \\
\text { chitosan, carbomer, or propylene } \\
\text { glycol as solubility enhancers. }\end{array}$ & $\begin{array}{l}\text { Hypromellose and carbomer had } 16- \\
\text { fold and } 20 \text {-fold improvement in mu- } \\
\text { coadhesion and release respectively. } \\
\text { Chitosan had a similar release. Pro- } \\
\text { pylene glycol had largest increase } \\
\text { from } \sim 25 \mu \mathrm{g} / \mathrm{cm} 2 \text { to } \sim 70 \mu \mathrm{g} / \mathrm{cm} 2 \text {. }\end{array}$ & 45 \\
\hline $\begin{array}{l}\text { Nasal Muco- } \\
\text { adhesive } \\
\text { Nanostruc- } \\
\text { tured Lipid } \\
\text { Carriers }\end{array}$ & $\begin{array}{l}\text { CBD-entrapped Micro- } \\
\text { Emulsion Nano-Lipid Car- } \\
\text { rier }\end{array}$ & Nasal & $\begin{array}{l}\text { Evaluating particle characteristics } \\
\text { and zeta potential of a nasal mucosal } \\
\text { microemulsion. }\end{array}$ & $\begin{array}{l}\text { Microemulsion lipid carriers were } \\
200 \mathrm{~nm} \text { in size, drug entrapment of } \\
99.99 \% \text {, drug loading of } 18.75 \% \text {, and } \\
\text { zeta potential was } 41 \pm 0.6 \mathrm{mV} \text {. }\end{array}$ & 46 \\
\hline $\begin{array}{l}\text { Ethyl Cellu- } \\
\text { lose-Based } \\
\text { Nanoparticu- } \\
\text { lates }\end{array}$ & $\begin{array}{l}\text { CBD-entrapped Ethyl Cel- } \\
\text { lulose Polymer }\end{array}$ & Topical & $\begin{array}{l}\text { Evaluation of nanoparticle entrap- } \\
\text { ment and keratinocyte toxicity. }\end{array}$ & $\begin{array}{l}\text { Nanoparticle size range of } 150-250 \\
\text { nm, with }>80 \% \text { drug entrapment. } \\
\text { Keratinocyte viability was } 80 \% \text { when } \\
\text { CBD concentrations ranged from } \\
0.66-6.6 \mu \mathrm{M} \text {. }\end{array}$ & 47 \\
\hline
\end{tabular}


This extract has been used to treat arthritic pains in the Middle East in creams, ointments, pastes, microemulsions, and gels. CBD has a relatively well-known anti-inflammatory effect which is thought to emulate the activity of acetylsalicylic acid. The objective of this patent is to create an anti-inflammatory emulsion of natural substances that limit side effects while having similar or better than current topical agents. No pharmacokinetic studies or tests have been conducted on these products.

\subsection{Nanoparticle Dosage Forms}

One of the significant areas of study in drug development and delivery is nanoparticles. $\mathrm{Na}-$ noparticles come in various shapes, sizes, and systems and can allow for reduced doses of medications needed and better targeting of therapies. For this reason, nanoparticles are the most studied systems to administer CBD. Therefore, the studies in this section are broad and encompass metal nanoparticles, liposomes, PLGA, and nanoliposphere-based nanoparticles (Table 4).

\subsubsection{Poly (lactic-co-glycolic acid) Micropar- ticles $^{34}$}

Fraguas-Sánchez et al. identified a potential drug delivery route for breast cancer and a synergistic effect with current treatments. CBDloaded microparticles were used in conjunction with paclitaxel (PTX) and doxorubicin (DOX) chemotherapy to treat breast cancer. The study was conducted based on the knowledge that CBD has an anti-proliferative effect, which triggers apoptosis via the direct/indirect activation of the cannabinoid receptor type- 2 and the vanilloid transient receptors. However, some cannabinoids still possess the possibility of proproliferative effects at nanomolar concentrations. Before this study was conducted, no known data existed on CBD at these concentrations. This led to the formation of microparticles to suspend CBD and slow its release.

Poly (lactic-co-glycolic acid) (PLGA) microparticles were created with an oil-in-water emulsion-solvent evaporation technique. The result was CBD encapsulated in PLGA microparticles. The exact modality of the synergism between CBD, PTX, and DOX is unknown. However, this study found that CBD loaded microparticles extended the breast cancer cell's anti-proliferative activity for at least 10 days as a monotherapy and in combination with PTX or
DOX. This noted synergism suggests that the effective concentrations of these antineoplastic agents in breast cancers cell lines (MDA-MB231 and MCF-7 cells) could be reduced. Fraguas-Sánchez et al. has shown in-vitro and inovo evidence of CBD-loaded microparticles having a synergistic effect with PTX and DOX chemotherapy of both estrogen receptor positive and triple negative breast cancers.

\subsubsection{Gold Nanoparticle Complex ${ }^{35}$}

Mokoena et al. created a gold nanoparticle (AuNP) complex with CBD to be infused and enhance breast cancer treatment. AuNPs can entrap a drug product and then be targeted by photodynamic laser therapy. These AuNPs travel through the bloodstream and escape the immune system's recognition. This prevents the CBD from being destroyed if it recognizes it as a foreign body. This system also limits the systemic side effects seeing as the lasers used will only target one specific area. The AuNPs are in a non-excited state when they are in the bloodstream or tissue and have not been targeted by the laser. When a laser hits these AuNPs, they enter an excited state. The CBD is then released from the AuNP complex to allow both products to express their effect. AuNPs can create ROS when in the excited state to kill the cancerous cell, while the CBD exerts its apoptosis effect.

The synergistic effect of the AuNP and CBD was evaluated in breast cancer but is theorized to work on other cancer cell lines. Results showed a reduction of the tumor size along with tumor removal.

\subsubsection{Poly-e-Caprolactone Microspheres ${ }^{36}$}

Poly- $\varepsilon$-caprolactone (PCL) microspheres are an oil-in-water emulsion prepared using solvent evaporation for the use of administering highly lipophilic drugs. Hernán Pérez De La Ossa et al. utilized this method to combat the problematic delivery of CBD through other methods. CBD was dissolved in dichloromethane and then briefly emulsified with aqueous polyvinyl alcohol. The emulsion was homogenized for 3 hours and then washed with deionized water, followed by filtration of the microspheres through a $5 \mu \mathrm{m}$ membrane filter. When stored, these microspheres were freeze-dried to prevent the molecules from experiencing polymer hydrolysis. Various drug/polymer ratios were tested from $5 / 150$ to $50 / 150$. The $50 / 150$ ratio could achieve a larger drug loading capability, 
$26.41 \mathrm{mg} \mathrm{CBD} / 100 \mathrm{mg}$ microparticles, compared to other ratios like $15 / 150,8.99 \pm 0.31 \mathrm{mg}$ $\mathrm{CBD} / 100 \mathrm{mg}$ microparticles. However, the encapsulation yield for $50 / 150$ was $\sim 59 \%$, while all others showed an $\sim 82 \%$ yield.

An in vitro study was performed on the various PCL microspheres to determine the efficacy of the CBD release and the ideal drug/polymer ratio. Researchers observed that the CBD had various stages of release at different temperatures, which were different for each drugpolymer ratio and believed to be a result of the CBD being dissolute to the superficial portion of the microspheres. This suggested that the drug formulation could be used for a sustained release formulation requiring reduced dosing to the patient. All formulations had a full drug release seen between 10-20 days. The 15/150 and $30 / 150 \mathrm{CBD} /$ microparticle ratio formulations were used in an in vitro tumor cell study. The CBD-infused microparticles showed more significant cell growth inhibition than the microparticle alone control. Days 4 and 7 showed significant levels of CBD released but then slowed after day 7 . The formulations would release a large quantity initially, followed by a sustained release after day 7 . The authors concluded that this could be a potential drug formulation for anti-tumor growth.

\subsubsection{PTL101 Oromucosal Spray ${ }^{37}$}

Jacob et al. studied the pharmacokinetic profile and relative bioavailability of CBD and THC through an oromucosal spray. Each 100$\mu \mathrm{L}$ oromucosal spray contained $2.7 \mathrm{mg}$ THC and $2.5 \mathrm{mg}$ CBD. PTL101 was made by incorporating CBD into an oral gelatin pellet matrix to allow better absorption and bioavailability. This drug was administered via the oromucosal route and was compared to pre-existing oromucosal products. This study found that the use of a PTL101 led to an increased $\mathrm{C}_{\max }$ and AUC at a $\mathrm{T}_{\max }$ of 33.5 hours.

The pharmacokinetic parameters were derived from data assembled from the drug's administration. With a 0.90 power analysis, a twosided statistical analysis was used to determine noninferiority. PTL101 was deemed safe and tolerable with no serious adverse effects and had no subject withdraws from the trial. The result showed that $10 \mathrm{mg}$ of the PTL101 formulation had a $\mathrm{C}_{\max }$ of $2.97 \mathrm{ng} / \mathrm{mL}$ and the $100 \mathrm{mg}$ dose had a $\mathrm{C}_{\max }$ of $43.42 \mathrm{ng} / \mathrm{mL}$. The $\mathrm{C}_{\max }$ of PTL101 was higher than that of the oromucosal spray with a $\mathrm{C}_{\max }$ of $1.8 \mathrm{ng} / \mathrm{mL}$. The oromucosal spray's $\mathrm{T}_{\max }$ was 2.92 hours and lower than the $10 \mathrm{mg}$ PTL101 dose at 2.97 hours and the 100 mg PTL101 dose at 3.45 hours. The $\mathrm{AUC}_{0 \text {-inf }}$ and $T_{1 / 2}$ of the $100 \mathrm{mg}$ dose were 153.04 $\mathrm{ng} * \mathrm{~h} / \mathrm{mL} ; 3.59$ hours; the $10 \mathrm{mg}$ was 10.31 $\mathrm{ng} * \mathrm{~h} / \mathrm{mL} ; 2.95$ hours. The $10 \mathrm{mg}$ dose of CBD in the PTL101 was found to have a $134 \%$ (90\%CI, 113-59\%) increase in bioavailability than the same dose of the oromucosal spray. The exposure to CBD increased in a dose-proportional manner. An increase in the CBD dose also increased $\mathrm{C}_{\max }$ and AUC. This dosage form resulted in a prolonged terminal elimination half-life which is ideal since CBD is highly lipophilic and accumulates in fatty tissue.

\subsubsection{PLT401 ${ }^{38}$}

An analysis of the pharmacokinetic profile of the PTL401 formulation showed higher AUC vs. time curves, half-life, $\mathrm{C}_{\max }$, and $\mathrm{T}_{\max }$ compared to pre-existing novel formulations. Most notably, the PTL401 formulations had $\mathrm{T}_{\max }$ values nearly half of traditional CBD formulations. This indicates that the PTL401 formulation could increase the $\mathrm{C}_{\max }$ in less time. Similarly, the PTL401 formulation reached $\sim 30 \%$ higher $\mathrm{C}_{\max }$ concentrations.

The PTL401 formulation showed a faster rate of absorption, improved bioavailability, and no significant increase in sight reactions, although past studies have indicated the possibility of undesirable oral effects, including discomfort, pain, dry mouth, and ulceration.

\subsubsection{Poly (lactic-co-glycolic acid) based Na- noparticles $^{39}$}

CBD has been a drug of high interest in cancer therapy because of its antitumor effects and palliative benefits. Because of this, both oral and topical CBD drug delivery has been explored, but unable to determine its effectiveness or safety due to CBD's low solubility and bioavailability. One method to overcome the solubility and bioavailability of CBD was the design of poly (D,L-lactide-co-glycolide) nanoparticles (PLGA NPs) by Martin-Banderas et al. Multiple PLGA NPs were made by coating the NP with poly (ethylene glycol) (PEGPLGA NPs), chitosan (CS) (CS-PLGA NPs), or pegylated chitosan (PEG-CS-PLGA NPs). Next, CBD was loaded by adding a CBD solution of acetone to each PLGA solution to generate the various PLGA NPs. These various 
PLGA NPs were then administered to mice to determine the anti-cancer tumor effect on a lung cancer cell line.

PLGA NPs had a mean particle size of $\sim 300$ $\mathrm{nm}$ and increased to $\sim 600 \mathrm{~nm}$ when PEG was incorporated and $\sim 700 \mathrm{~nm}$ when also incorporated with CS. Drug loading efficiency was not significantly improved when adding PEG or CS. A total of 40 mice were used to allow 10 mice to be tested for each of the four different PLGA NPs. The mice had the PLGA NPs administered every 3 days for 21 days and were dosed at $5 \mathrm{mg} / \mathrm{kg}$ based on each mouse's initial weight. Results were observed for 41 days. Results showed that PLGA NPs and PEG-CSPLGA NPs followed similar drug release profiles. CS-PLGA NPs had slower release levels than the PLGA NPs, but PEG-PLGA NPs had a significantly faster release. On day 9, PEGPLGA had released $\sim 60 \%$, PEG-CS-PLGA NPs and PLGA NPs had released $\sim 25 \%$, and CS-PLGA had released $\sim 5 \%$ of the drug product. On day 30, PEG-PLGA had released $\sim 85 \%$, PEG-CS-PLGA NPs and PLGA NPs had released $\sim 65 \%$, and CS-PLGA had released $\sim 57 \%$ of the drug product. What was seen was a sustained level of drug release by most of the PLGA NPs, and the PEG-PLGA having an initial burst of the drug being released. PEG-CSPLGA NPs, PLGA NPs, and CS-PLGA NPs were found to have no significant difference compared to a control cannabinoid group. PEGPLGA NPs had a 2.2-fold reduction in tumor volume on day 32 compared to the control group. On day 41, a 1.5-fold decrease was observed.

\subsubsection{Pro-NanoLipospheres ${ }^{40}$}

Cherniakov et al. designed a formulation that created a nanoliposphere that enhanced oral absorption in rats. The self-emulsifying product was developed by taking Pro Nanoliposphere (PNL) pre-concentrates to enhance phase I metabolism and bioavailability. The PNL is a formulation composed of lipid and emulsifying excipients, which are generally recognized as safe by the FDA; the formulation is known to increase solubility and reduce phase 1 metabolism of specific, commonly lipophilic, active compounds. The research team made separate formulations containing either piperine, resveratrol, or curcumin infused with $\mathrm{CBD}$ and THC at a 1:10 dilution of the preconcentrated
PNL solution. Each product was studied, evaluating the pharmacokinetics compared to a CBD solution.

The piperine-PNL formulation resulted in a 6fold AUC increase compared to the CBD solution. In addition, bioavailability showed a 2fold increase in the CBD-piperine-PNL formulation compared to the CBD solution, allowing the authors to conclude that the piperine component increases bioavailability. This was confirmed when testing a CBD-piperine solution without the PNL component compared to just CBD.

\subsubsection{Piperine-pro-nanolipospheres ${ }^{41}$}

Cherniakov et al. prepared a specialized piperine-pro-nanoliposphere formulation, resulting in a 3-fold increase in $\mathrm{C}_{\max }$ and a 1.5-fold increase in AUC compared to Sativex, a buccal formulation. Furthermore, each formulation held a 1:1 ratio of THC:CBD, averaging $\sim 10$ $\mathrm{mg}$ in each category. Therefore, a simple comparison of the achieved $\mathrm{C}_{\max }$ and $\mathrm{AUC}$ for each formulation will show whether the oral formulation can compete.

Piperine was added to act on the first-pass metabolism by inhibiting pathways that metabolize THC/CBD, thus increasing the amount that reaches circulation. In many ways, this is a drug interaction study in which the authors explore the idea of using selective inhibition. However, a non-piperine formulation was not added to the study as a standard control comparison. The study suggests piperine itself was critical to the solution.

The authors suggest this study could show the potential of a standardized formulation despite showing mild-moderate side-effects in half of the participants.

\subsubsection{Nanostructured Lipid Carriers ${ }^{42}$}

Esposito et al. used nanostructured lipid carriers URB597, AM251, and rimonabant to encapsulate cannabinoid drugs. Lipid melting and ultrasonication were used to make the nanolipid carriers. The lipid melting process was done by having the oil phase added to the water phase, and ultrasonication was done by having the water phase added to the oil phase. The oil phases were constructed of a 2:1 tristearin/miglyol lipid mixture, and the water phase was constructed of a $2.5 \%$ aqueous poloxamer 188 solution. Cannabinoids were added during the nanolipid production with the oil phase. Then, 
the nanolipid carrier was added to methanol and loaded in a centrifugal filter, and centrifuged to determine the amount of cannabinoid that could be encapsulated.

The properties of each formulation were studied to determine the optimal formulation. URB597 and AM251 achieved concentrations of $4.00 \mu \mathrm{g} / \mathrm{mg}$ of the oil phase used. The rimonabant formulations were found to have a 10 -fold increase in loading at $40.00 \mu \mathrm{g} / \mathrm{mg}$. In addition, the URB597 and AM251 had recovery rates of $98.0 \%$ and $98.8 \%$, respectively, while the rimonabant had a $92.5 \%$ recovery. Therefore, the authors concluded that any formulations would be beneficial for study and practical use to help deliver expensive cannabinoid products.

\subsubsection{Calcium Alginate Liposomal Suspen- $\operatorname{sion}^{43}$}

Monshipouri et al. have a patent pending that details encapsulation by liposomal suspensions with calcium alginate. The encapsulation process involves crosslinking a sodium alginate nanogel with calcium alginate followed by liposomal encapsulation through the same method. Terpenes and cannabinoids are added prior to the crosslinking. This would allow CBD in the crosslinked nanogel and the liposomal space.

The distribution of the CBD is thought to be controlled with more accuracy in the nanogel and liposomal space. The API dissolved in the liposomal space would be able to metabolize initially and then have the nanogel metabolized after that. This would allow for a prolonged AUC and $\mathrm{C}_{\max }$. This method is thought to provide more accurate dosing and a prolonged drug release.

\subsubsection{Electrospun Fibers ${ }^{44}$}

Eleftherios et al. designed an orally delivered CBD formulation using water-soluble electrospun fibers. CBD, and cannabigerol (CBG), were formulated with polyvinyl(pyrrolidone) and Eudragit L-100 at a 1:1 molar ration through electrohydrodynamic atomization. The solutions were made using $10 \%$ and $20 \% \mathrm{w} / \mathrm{v}$ solutions polyvinyl(pyrrolidone) and Eudragit L-100 in ethanol at room temperature using magnetic stirring for 30 minutes. The formed fibers were then analyzed using peri dish methods for length, encapsulation, and in vitro drug release.
The study team stated that the spun fibers were seen to be smooth and uniform with a fiber diameter range of 700-900 $\mathrm{nm}$ for the polyvinyl(pyrrolidone) fibers and $1-5 \mu \mathrm{m}$ for the Eudragit L-100 fibers. Encapsulation was reported as $90 \%$ for both the $10 \%$ and $20 \% \mathrm{w} / \mathrm{v}$ formulations. In vitro tests determine that gastric fluid and intestinal fluids were stimulated by the fibers and increased CBD and CBG.

3.5.12. Mucoadhesive Buccal Silica Formulations $^{45}$

Sopper et al. generated mucoadhesive and mucopenetrative buccal nanoparticles by forming silica-loaded CBD. The silica carrier was formed by loading Aeroperl 300 with CBD by drying aeroperl 300 for $30 \mathrm{~min}$ at $110^{\circ} \mathrm{C}$ and subsequently mixing an ethanolic $\mathrm{CBD}$ solution at low speed for 4 minutes. Hypromellose, chitosan, carbomer, or propylene glycol were added to the mixture to create a nanoparticle solution to increase drug permeability. Drug dissolution was tested using a $\mathrm{Ph}$.Eur paddle dissolution apparatus at $37^{\circ} \mathrm{C}$ at a stir speed of 65 rpm. Mucoadhesion was tested through modified porcine buccal cells fixed in place and warmed to $\sim 37^{\circ} \mathrm{C}$ with artificial saliva added to prevent drying. Results showed that the addition of hypromellose and carbomer resulted in a 16-fold and 20-fold improvement of mucoadhesion over 60 minutes, $\sim 45 \%$ and $\sim 75 \%$, respectively. This was compared to an Aeroperl 300 carrier at $\sim 20 \%$ over 60 minutes. Chitosan showed a similar release mucoadhesive release as the Aeroperl 300 carriers. Propylene glycol's addition increased the permeability of CBD from $\sim 25 \mu \mathrm{g} / \mathrm{cm}^{2}$ to $\sim 70 \mu \mathrm{g} / \mathrm{cm}^{2}$ for Aeroperl 300 carriers, but similar results for all other formulations.

\subsubsection{Nasal Mucoadhesive Nanostructured Lipid Carriers ${ }^{46}$}

Matarazzo et al. generated nanostructured lipid carriers for the nasal administration of CBD using positively charged surface particles. The hot micro-emulsions technique was used to form the nanolipid carriers by combining $1.25 \%$ stearic acid, $0.75 \%$ oleic acid, $0.25 \%$ Span 20 , and $0.05 \%$ cetylpyridinium chloride through heating at $85^{\circ} \mathrm{C}$, followed by the addition of $150 \mathrm{mg}$ CBD. The microemulsion is formed when $300 \mu \mathrm{L}$ of purified was added, followed by dripping over $20 \mathrm{~mL}$ of purified ice. 
Particle size, entrapment of CBD, and zeta potential were then analyzed. Particle size and zeta entrapment were determined using dynamic light scattering, while drug entrapment was determined using ultrafiltration/centrifugation.

Lipid carriers were determined to be uniform in size at $200 \mathrm{~nm}$. The carriers showed drug entrapment of $99.99 \%$, with a drug loading level of $18.75 \%$. Zeta potential was calculated to be $41 \pm 0.6 \mathrm{mV}$. It was reported that the zeta potential should increase the surface binding and drug uptake in the nasal mucosa due to mucin being a large, negatively charged glycoprotein.

\subsubsection{Ethyl Cellulose-Based Nanoparticu-} lates $^{47}$

A pre-proof article by Zamansky et al. used nanoprecipitation to form nanoparticles using ethylcellulose to entrap CBD and curcumin. The nanoparticles were formed by dissolving $1.5 \% \mathrm{w} / \mathrm{w}$ ethyl cellulose grades 7 and std. 100 , $0.30 \% \mathrm{w} / \mathrm{w}$ cetyl alcohol or triethyl citrate, and $0.075 \mathrm{w} / \mathrm{w}$ CBD in ethanol stirred at 700 rpm. Deionized water was added until a $60 \% \mathrm{w} / \mathrm{w}$ dispersion mass was achieved. This was then rotary evaporated until a four times size reduction in volume was achieved, then lipolyzed with mannitol. Dynamic light scattering was used to determine particle size and drug entrapment.

Nanoparticles were determined to have a 150 $250 \mathrm{~nm}$ size with an entrapment efficiency $>80 \%$. Aggregation was reduced in this lipid complex when the CBD:polymer ratio had higher proportions of polymer. High polymer saturation increased the formation rate of polymer cores and decreased polymer layering of existing cores, and reduced particle size formation, increasing entrapment efficiency. Keratinocyte toxicity was subsequently analyzed and seen that $\mathrm{CBD}$ concentrations ranging from $0.66-6.6 \mu \mathrm{M}$ maintained cell viability at $80 \%$ compared to a control of just the drug vehicle.

\subsection{Miscellaneous Dosage Forms}

Some CBD formulations were provided as an intravenous injection or as an inhalant (Table 5). These studies were primarily focused on pharmacokinetics and the effects of CBD as an antidepressant.

Table 5. Summary of articles classified under various dosage forms.

\begin{tabular}{|c|c|c|c|c|c|}
\hline Name & $\begin{array}{l}\text { Formula- } \\
\text { tion }\end{array}$ & Delivery & Study Characteristics & Results & $\begin{array}{l}\text { Cita- } \\
\text { tion }\end{array}$ \\
\hline Vaporized & $\begin{array}{l}\text { CBD Vapor } \\
\text { Inhalant }\end{array}$ & Inhalation & $\begin{array}{l}\text { Vaporized CBD study evaluating } \\
\text { blood serum levels, core body tem- } \\
\text { perature, level of activity, and ef- } \\
\text { fects when administered with nic- } \\
\text { otine. }\end{array}$ & $\begin{array}{l}\text { Decrease }(p \leq 0.0001) \text { in core } \\
\text { body temperature by } 7.54^{\circ} \mathrm{F} \text {. }\end{array}$ & 48 \\
\hline Intravenous & $\begin{array}{l}\text { CBD-loaded } \\
\text { IV Lipid } \\
\text { Emulsion }\end{array}$ & IV & $\begin{array}{l}\text { Study comparing intravenous } \\
\text { (IV) CBD in treating depression in } \\
\text { a chronic mild stress mouse mode } \\
\text { versus traditional oral formula- } \\
\text { tions. }\end{array}$ & $\begin{array}{l}\text { IV-CBD formulation reached } \\
\text { peak plasma concentrations } \\
\text { within } 10 \text { minutes compared } \\
\text { to } 80 \text { minutes for the oral for- } \\
\text { mulation. }\end{array}$ & 49 \\
\hline Smoked & $\begin{array}{l}\text { Combusted } \\
\text { Cannabis } \\
\text { Plant Inhal- } \\
\text { ant }\end{array}$ & Inhalation & $\begin{array}{l}\text { Comparison of 9-Tetrahydro- } \\
\text { cannabinol (THC), 11- hydroxy- } \\
\text { THC (11-OH-THC), 11-nor-9-car- } \\
\text { boxy- THC (THCCOOH), canna- } \\
\text { binol (CBN) and cannabidiol } \\
\text { (CBD) blood serum levels in fre- } \\
\text { quent and occasional cannabis } \\
\text { smokers. }\end{array}$ & $\begin{array}{l}\text { THC-COOH blood and } \\
\text { plasma concentrations in fre- } \\
\text { quent smokers were greater } \\
\text { with a } 6-\mathrm{h} \text { blood median level } \\
\text { of } 23.9 \mathrm{mg} / \mathrm{L} \text {. }\end{array}$ & 50 \\
\hline $\begin{array}{l}\text { Dry Powder } \\
\text { Inhalation }\end{array}$ & $\begin{array}{l}\text { Single-Use } \\
\text { CBD Dry } \\
\text { Powder In- } \\
\text { haler }\end{array}$ & Inhalation & $\begin{array}{l}\text { Phase } 1 \text { drug clinical trial using } \\
\text { single-use cartridges for PK/PK } \\
\text { parameters in healthy adults. }\end{array}$ & $\begin{array}{l}\text { AUC of } 182.5 \mathrm{ng} * \mathrm{~h} / \mathrm{mL} \text {, } \\
\mathrm{C}_{\max } 447 \mathrm{ng} / \mathrm{mL} \text {, and peak } \\
\text { CBD concentration time of } 3.8 \\
\text { minutes. }\end{array}$ & 51 \\
\hline $\begin{array}{l}\text { Microdepot } \\
\text { Controlled } \\
\text { Release }\end{array}$ & $\begin{array}{l}\text { CBD Loaded } \\
\text { Polycapro- } \\
\text { lactone Mi- } \\
\text { crodepot }\end{array}$ & Intramuscular & $\begin{array}{l}\text { Evaluation in mice for drug re- } \\
\text { lease, and the incidence, survival } \\
\text { rate, and latency of tonic-clonic } \\
\text { seizures in mice over } 2 \text { weeks. }\end{array}$ & $\begin{array}{l}\text { The average particle size of } \\
257.80 \pm 2.49 \mu \mathrm{m} . \sim 70 \% \text { drug } \\
\text { released over } 2 \text { weeks. Inci- } \\
\text { dence of tonic-clonic seizures } \\
\text { reduced by } 40 \% \text {, with survival } \\
\text { and latency increasing by } 50 \% \\
\text { and } 170 \% \text {, respectively. }\end{array}$ & 52 \\
\hline
\end{tabular}




\subsubsection{Vaporized 48}

A CBD vapor inhalant was designed by designing an e-cigarette vapor in Mehrak et al. This method creates a hot vapor from liquid CBD for inhalation. Inhalation of CBD products is a novel form of delivery, but a vapor pen is a newer form of administration. The effects of vaporized $\mathrm{CBD}$ were evaluated on the blood serum levels, core body temperature, level of activity, and effects when administered with nicotine. Two concentrations of CBD were used, $100 \mathrm{mg} / \mathrm{mL}$ and $400 \mathrm{mg} / \mathrm{mL}$. The CBD formulation was then compared to positive controls of a 5-HT $1 \mathrm{~A}$ agonist (8-OH-DPAT) and 5$\mathrm{HT}_{7}$ antagonist (WAY 100,635) administered via injection.

CBD plasma concentrations showed a significant difference $(\mathrm{P} \leq 0.05)$ based on sex. Heavy rats (by weight) showed greater serum concentrations. ANOVA data showed a significant decrease $(p \leq 0.0001)$ in core body temperature by $7.54^{\circ} \mathrm{F}$, and the time after inhalation affected the rate of activity, 9.02 counts/minute ( $\mathrm{p} \leq$ 0.0001 ). Some rats were given $30 \mathrm{mg} / \mathrm{mL}$ of nicotine with the CBD vapor products and found that the activity rate was significantly higher $(\mathrm{p} \leq 0.0001)$ over time when co-administered

\subsubsection{Intravenous ${ }^{49}$}

$\mathrm{Xu}$ et al. pursued intravenous (IV) CBD in the treatment of depression in a chronic mild stress mouse model. The IV CBD formulation was prepared by adding CBD to a lipid emulsion, forming a homogenous product. The product was then injected as a parenteral nutrition agent. The mice were evaluated cognitively with a chronic mild stress program and a forced swim test. Their pharmacokinetics were assessed by examining AUC and MRT (mean residence time). It was found that periodic administration of IV-CBD notably reduced depression-induced symptoms and significantly improved depressive behavior. However, the forced swim test produced no notable change in behavior. Pharmacokinetic analysis of the IV-CBD formulation was compared to a traditional oral formulation, which showed that the IV-CBD formulation reached peak plasma concentrations within 10 minutes compared to 80 minutes for the oral formulation. Additionally, the IV-CBD formulation maintained significantly higher plasma concentrations for longer periods and matched the peak plasma concentration of the oral formulation for an average of 8-12 hours. Overall, the results showed that IV-CBD allows for more bioavailability when compared to oral options.

\subsubsection{Smoked50}

Desrosiers et al. compared 9-Tetrahydrocannabinol (THC), 11- hydroxy-THC (11-OHTHC), 11-nor-9-carboxy- THC (THCCOOH), cannabinol $(\mathrm{CBN})$, and $\mathrm{CBD}$ in frequent and occasional cannabis smokers. These compounds have been reported in blood from frequent cannabis smokers for an extended time during abstinence. THC is the primary psychoactive ingredient in cannabis and is rapidly metabolized to the active $11-\mathrm{OH}-\mathrm{THC}$ by cytochrome $\mathrm{P} 450$ 2C9, 2C19, and 3A4 in 13 mins after smoking and reaching $10 \%$ of THC concentrations. The study showed THC- $\mathrm{COOH}$ and THC-COO-glucuronide were significantly higher in frequent smokers' blood and plasma at all time points. The THC-COOH blood and plasma concentrations in regular smokers were more significant with a 6-h blood median level of $23.9 \mathrm{mg} / \mathrm{L}$. The results showed that CBD and CBN were detected shorter times than THC and THC-glucuronide. Blood and plasma $\mathrm{CBN}$ and plasma $\mathrm{CBD} \mathrm{C}_{\max }$ were larger in frequent smokers. In conclusion, the study performed simultaneous THC, 11-OH-THC, THCCOOH, CBD, CBN, THC-glucuronide, and THCCOO-glucuronide analysis in blood and plasma from frequent and occasional smokers following controlled cannabis smoking. THC, 11- OH-THC, $\mathrm{THCCOOH}$, and THCCOO-glucuronide were significantly higher in frequent smokers than occasional smokers, even after correcting for baseline concentrations. The authors concluded that $\mathrm{CBD}, \mathrm{CBN}$, and THC-glucuronide could be used as inclusionary markers of recent use.

\subsubsection{Dry Powder Inhalation ${ }^{51}$}

A pre-proof journal by Devinsky et al. evaluated the bioavailability of a dry powder formulation of CBD in a Phase-1 clinical trial. Hemp isolate containing $\sim 99 \%$ CBD was prepared through spray drying and then added to 200 proof ethanol. A solution of 1,2-distearoyl-snglycero-3-phosphocholine in 200 proof ethanol was prepared and then added to the CBD solution. Fumaryl diketopiperazine, ethanol, and water were added to this final solution and mixed. The mixture was then spray dried. The formulation was then given to healthy participants aged 21-55 and contained $10 \mathrm{mg}$ powder in single-use cartridges, which contained $2.1 \mathrm{mg}$ CBD. This was compared to Epidiolex $50 \mathrm{mg}$ CBD and had the $\mathrm{C}_{\max }$ and AUC tested over 12 hours. 
The AUC for oral Epidiolex was 20.0 $\mathrm{hr} * \mathrm{ng} / \mathrm{mL}$ and $182.5 \mathrm{hr} * \mathrm{ng} / \mathrm{mL}$ for inhaled CBD. $\mathrm{C}_{\max }$ was $6.3 \mathrm{ng} / \mathrm{mL}$ in the Epidiolex group and $447 \mathrm{ng} / \mathrm{mL}$ in the inhalation group. Inhalation increases the bioavailability of CBD by 9.1-fold for AUC and 71-fold for $\mathrm{C}_{\max }$ compared to Epidiolex. The peak time for the inhaled formulation was found to be at 3.8 minutes, compared to 121.8 minutes for the Epidiolex group.

\subsubsection{Microdepot Controlled Release ${ }^{52}$}

Uziel et al. generated a multiple phytocannibidiol drug-releasing microdepot formulation to allow for a controlled release of various cannabinoids. Microdepots were created using molten polycaprolactone with a $30 \% \mathrm{CBD}$ extract at $60^{\circ} \mathrm{C}$, followed by the mixture being spray dried and stored at $-4^{\circ} \mathrm{C}$. This formulation was then administered to mice to determine the drug's release and pharmacokinetics. Mice weighed 20-25 $\mathrm{g}$ and were treated with either a $200 \mathrm{mg} / \mathrm{kg}$ dose of the CBD microdepot or CBD extract solution. The microdepot was stabilized by suspending $1 \mathrm{~mL}$ of the mixture in a $1 \% \mathrm{w} / \mathrm{w}$ carboxymethylcellulose and $1 \% \mathrm{w} / \mathrm{w}$ Tween 20 in saline solution. Mice were then evaluated for the time it took until a tonic-clonic seizure occurred in both treatment arms.

The microspheres preserved their spherical shape during solidification and turned brown. Scanning electron microscopy images showed the spheres were uniform and formed distinct non-smooth textures. Laser diffraction analysis was done to determine particle size and found to be $257.80 \pm 2.49 \mu \mathrm{m}$ on average. The drug release was reported to be $\sim 70 \%$ over 2 weeks and concluded that a sustained release was maintained. After one week, the incidence of tonicclonic seizures decreased by $40 \%$, the survival rate increased by $50 \%$, and the latency till the first tonic-clonic seizures by $170 \%$.

\section{Discussion}

It is essential to look at the purpose of each delivery system individually and within its subclass. For example, a nanoparticle-based formulation may be ideal for a specific disease state but may not be ideal for a generalized condition. In this situation, an emulsion or conventional dosage form may be more ideal. To fairly compare these delivery systems, we have discussed them by subclass and not as a whole entity. It is also relevant to point out that there are too many over-the-counter CBD-based products that could not be evaluated due to the lack of published materials and unregulated nature of those products. There are, however, some products that are more reputable than others and are the most purchased agents available (Table $6)$.

\section{Conventional Dosage Forms}

Conventional dosage forms are the most common mode of cannabinoid drug delivery and include the clinically available formulations. Clinically, however, many of these formulations are only available for specific disease states and are difficult to obtain prescriptions for outside their mandated scope by the FDA. Nabiximols, brand name Sativex, is a formulation being employed as a novel treatment for cannabis withdrawal.

While colloquially, cannabis is thought to have no physical withdrawal symptoms and is clinically thought only to elicit psychological withdrawal symptoms, this is thought to be due to the desensitization and downregulation of $\mathrm{CB}$ receptors and neuroplasticity. ${ }^{61}$

Nabiximol, when compared to dronabinol, was shown to elicit greater efficacy in the treatment of cannabis withdrawal. ${ }^{16}$ Additionally, the added effect of THC in the formulation likely prevents the withdrawal symptoms associated with the general lack of THC in the system after cannabis discontinuation. ${ }^{16}$

Overall, this study indicates that CBD-based formulations, and titrated amounts of THC, allowing for an adequate cannabinoid replacement therapeutic option. Most recently, this food effect has been reviewed in applying CBD to epilepsy patients in both a fed state and a fasting state. Overall, the results are inarguably supporting the increase in dietary supplementation's bioavailability on CBD absorption. ${ }^{17}$ Marketing supplements toward pets is a lucrative and growing business valued at 0.637 billion USD annually with a market growth rate of approximately $1 \%$; it is a wealth market worth exploring and investing. ${ }^{63}$ Therefore, studies that validate pets' safety, efficacy, tolerability, and use offer significant value. Overall, while this study was only conducted through online surveys, it shows that the tolerability of cannabinoids in pets is significant. ${ }^{18}$ 
Table 6. Top-selling over-the-counter CBD products for edible gummies/capsules, oral/sublingual tinctures, topical/transdermal agents, and cannabis flowers.

\begin{tabular}{|c|c|c|c|c|}
\hline Dosage Form & Products $^{53-60}$ & Delivery & $\begin{array}{l}\text { Availabil- } \\
\text { ity }\end{array}$ & $\begin{array}{c}\text { PK/PD } \\
\left.\left.\text { AUC, } T_{\max }\right)\right)^{6}\end{array}$ \\
\hline $\begin{array}{l}\text { Edible Gummies/Cap- } \\
\text { sules }\end{array}$ & $\begin{array}{l}\text { Holmes Organic Premium Grade } \\
\text { CBD Gummies } \\
\text { Saha Self-Care Premium Nano CBD } \\
\text { Softgels } \\
\text { Sunsoil CBD Oil Vegan Capsules } \\
\text { Charlotte's Web CBD Gummies }\end{array}$ & Oral & \multirow{3}{*}{$\begin{array}{l}\text { Pure CBD, } \\
\text { Broad-Spec- } \\
\text { trum, and } \\
\text { Full-Spec- } \\
\text { trum formu- } \\
\text { lations }\end{array}$} & N/A \\
\hline Oral/SL Tinctures & $\begin{array}{l}\text { Joy Organics Organic CBD Oil } \\
\text { R+R Medicinals Organic Broad- } \\
\text { Spectrum THC-Free Hemp Extract } \\
\text { Tincture } \\
\text { Charlotte's Web CBD Oil }\end{array}$ & Oral & & $\begin{array}{l}\text { SL: } \sim 2.5 \mathrm{ng} / \mathrm{mL} \text {, } \\
3.49 \mathrm{ng} * \mathrm{~h} / \mathrm{mL}, \sim 1.6 \\
\text { hours } \\
\text { Oral: } 1.13 \mathrm{ng} / \mathrm{mL}, \\
4.4 \mathrm{ng} * \mathrm{~h} / \mathrm{mL}, \sim 1.07 \\
\text { hours }\end{array}$ \\
\hline $\begin{array}{l}\text { Topicals (creams, } \\
\text { ointments, sprays) }\end{array}$ & $\begin{array}{l}\text { Cornbread Hemp CBD Lotion Skin } \\
\text { Formula } \\
\text { Medterra Pain Relief Cream } \\
\text { Charlotte's Web Full Spectrum } \\
\text { Hemp Extract Cream }\end{array}$ & Topical & & N/A \\
\hline Cannabis Flower & Distributors vary & $\begin{array}{l}\text { Oral/Inhala- } \\
\text { tion/SL }\end{array}$ & $\begin{array}{l}\text { Herb flow- } \\
\text { ers, canna- } \\
\text { binoid pro- } \\
\text { file varies }\end{array}$ & $\begin{array}{l}\text { Varies in individu- } \\
\text { als based on cannabis } \\
\text { use frequency. }\end{array}$ \\
\hline
\end{tabular}

Epidiolex is the only FDA-approved pure CBD formulation on the market and is only considered for specific seizure syndromes. Dosing of this medication was found to have a safe upper limit of $10 \mathrm{mg} / \mathrm{kg}$ twice daily. ${ }^{19}$

The cannabinoid system is thought to play a critical role in obesity, specifically in regulating thermogenesis, food intake, and inflammation. ${ }^{64}$ Generally, adipose tissue comprises of three cell types; these include white adipocytes, which are responsible for fat storage and hormone secretion; brown adipocytes, which are directly involved in thermogenesis and caloric expenditure; and beige adipocytes, which act as transitional adipocytes, which are thought to respond to various stimuli flipping to white or brown adipocytes - these are thought to be protective against obesity and enhance energy expenditure. These beige adipocytes are thought to be a new therapeutic target for obesity. ${ }^{64}$ Therefore, a study exploring the use of subcutaneous CBDs effect on adipose tissue is welltimed and offers insight into a possible application of CBD in the treatment of obesity - a growing public health crisis globally. ${ }^{20,64}$ Overall, this study found that when compared to the placebo ( $70 \%$ ethanol) subcutaneous injection, the CBD formulation elicited a significant change in the inflammation, degradation, and necrosis of adipose tissue while also exhibiting an anti-anxiolytic effect in the participant rats as well. ${ }^{20}$ These findings offer a unique thought for future research exploring the use of SQ CBD in treating obesity, albeit further animal studies or a clinical study. The market for supplements geared toward obesity accounts for 2 billion USD of the 140 billion USD total market. ${ }^{65}$ This offers a substantial projection of the value a product like SQ CBD could have as a clinically available treatment option for patients suffering from obesity.

Opioid use, abuse, and place in pain treatment have come into serious question in the last few years. A combination of shrewd marketing, political wrangling, and lobbying tactics, combined with physician-led over-prescribing, are just a few of the reasons the opioid public health crisis has become such a landmark of the last few decades. ${ }^{66}$ Therefore, research investigating the possibility of decreasing the burden of addiction in patients prescribed these medications is critical. This study examined mixed cannabinoid soft gels in the de-escalation of opioid use in patients. Finding that over half of the patients could reduce their opioid burden in 
just 8 weeks is a strong indicator for the possibility of a future novel target. While the precise mode of such an occurrence would require further pharmacological analysis, a $53.2 \%$ success rate among participants is statistically significant. ${ }^{21}$ Future trials examining these findings further in more extensive clinical settings would provide more data to determine a path for therapeutically applicable opioid de-escalation regimens.

\section{Transdermal Dosage Forms}

Transdermal dosing of cannabinoids may be the most difficult formulation to achieve systemic concentrations. It is well known that cannabinoids are lipophilic, and therefore their ability to cross the lipophilic membrane of skin cells is impeded. Topical formulations that employ cannabinoids could be revolutionary in treating localized pain, nerve pain, arthritis, and neuralgia; likewise, transdermal delivery of cannabinoids could bypass first-pass metabolism - theoretically enhancing the therapeutic profile of the compounds. The study utilizing extract in olive oil found a reduction in pain for $\sim 70 \%$ of the treatment group. This indicates significant results compared to the $9.81 \%$ reduction offered by the placebo group. ${ }^{22}$ These results are also confounding because an olive oil preparation for CBD delivery should not be very bioavailable as a topical. A study of dosing participants that measured their body-surface area and then their serum concentrations would reveal just how much of the CBD is penetrating their system. However, at face value, this study's findings indicate that simple oil preparations may be adequate delivery methods for CBD in the treatment of muscle pain. The study of a propylene glycol CBD formulation indicated that the CBD could penetrate the skin barrier and achieve systemic concentrations. The $\mathrm{C}_{\max }$ value was measured at $\sim 8.3 \mathrm{ng} / \mathrm{mL}$, which is comparable to the concentration achieved by oral methodology. ${ }^{23}$

An ethosome is a phospholipid nanovesicle, similar to a liposome. The idea to use liposomal carriers to deliver drugs to targets better is by no means novel. However, they have yet to employ this tactic in delivering autoimmune modulators. This study showed that ethosomal carriers do not undergo degradation under normal physiologic conditions. ${ }^{22}$ These findings mean that ethosomal carriers can be used in the safe delivery of lipophilic medications without product loss to target. ${ }^{24}$ Overall, these findings show ethosomal carriers may be practical delivery mechanisms for products such as cannabinoids to be employed in treating autoimmune disease states affecting joints and ligaments.

Of the various patents explored, only one showed great value from a therapeutic and practical sense. The topical spray, emu oil, and camphor formulations utilize classical methodologies in topical application. ${ }^{25,26,46}$ While it is likely they may offer some penetration through the skin, because of the lipophilic nature of cannabinoids, it is unlikely that a simple alcohol solution acts as an adequate vehicle for the transportation of cannabinoids across skin cell and mucosal membranes. ${ }^{3}$ The most promising theoretical, topical formulation is a microneedle administered hydrogel. It is both an ambitious and novel therapeutic technique. The general concept is to dissolve cannabinoids within a hydrogel matrix and fill a microneedle apparatus with the material. The hydrogel would then be drawn in subcutaneously, exerting its action and eventually reaching the systemic circulation. ${ }^{27}$ While the patent itself does not offer data to support the idea, hydrogels have been used as pharmaceutical deliverables before, most commonly in wound dressing. ${ }^{67}$ Therefore, it is practical that a hydrogel containing cannabinoids could be topically delivered through a microneedle apparatus. Development of this product, and future research into its clinical use, efficacy, safety, and tolerability should be observed with optimistic curiosity. Products like this may serve as the most accurate method of delivering cannabinoids systemically while simultaneously bypassing first-pass metabolism. ${ }^{23}$ This can be seen to have great potential due to thermoresponsive microgel transdermal patches having excellent drug release properties when tested on mucosal cells. ${ }^{29}$

\section{Emulsion Based Dosage Forms}

Emulsion-based drug delivery systems utilize surfactant-lipid combinations to enhance the hydrophilicity of micelles. This allows for greater intestinal absorption. The studies reviewed in this category focus on the bioavailability of these formulations via an analysis of $\mathrm{C}_{\max }, \mathrm{T}_{\max }$, and AUC. The VESIsorb Self-Emulsifying Drug Delivery System spontaneously emulsifies in the gastric and intestinal fluids, allowing trapped lipophilic drug product to pass 
through the lumen - thus increasing its bioavailability. ${ }^{30}$ On average, this system was shown to be $3 \times$ more effective in CBD delivery when compared to traditional MCT CBD formulations. ${ }^{30}$ The nanoemulsion prepared by Nakano et al. utilized a combination of surfactant, wetting agent, preservative, and aqueous phase to create a novel nanoemulsion base. ${ }^{31}$ Overall, this study showed the necessity of bile in the sequestration of lipids through the gastrointestinal tract and proved that formulations that, in effect, salt works to increase the bioavailability of $\mathrm{CBD} .^{31}$ This formulation was shown to have a superior $\mathrm{T}_{\max }$ and AUC compared to traditional oil formulations - further evidence that emulsion-based formulation creates ideal environments for lipophilic drug absorption. Izegelov et al. explored nano-emulsified triglycerides, specifically LCT vs. MCT. Overall, they found that LCT formulations enhanced $\mathrm{C}_{\max }$ and AUC; however, MCT formulations had quicker onsets of action. ${ }^{68}$ This difference in bioavailability is likely due to differing fat absorption kinetics and indicates further in-vivo studies into the kinetics of emulsionbased formulations. The use of silicone and hyaluronic acid to assist with wound management is an interesting patent that should be studied in controlled conditions; however, without substantial data, no further analysis can be served. Likewise, the use of boswellic acids could be another novel emulsion formulation; however, further studies should be conducted because no data exist concerning its use in controlled conditions. $^{32,33}$

\section{Nanoparticle Dosage Forms}

"Nanoparticle" is a broad term used to describe many objects at the nanometer level, e.g., metal nanoparticles, liposomes, PLGA, and nanoliposphere-based nanoparticles. These particles may form metal-organic frameworks, micelles, or highly manufactured proteins at the molecular level. Poly(lactic-co-glycolic acid) microparticles were found to elicit synergistic effects with the chemotherapeutic paclitaxel and doxorubicin. While these microparticles were created in an oil-in-water emulsion, synthesized with solvent evaporation techniques, the overarching theme of the study was to explore the pharmacological implications of CBD dosing coinciding with chemotherapy. Overall, the findings indicate synergistic effect - by this token alone, the modality of CBDs effect on chemotherapy warrants further exploration. ${ }^{34}$ Gold nanoparticles are complexations that have been used as a subject of experimentation and therapeutic application - most notably in cancer treatments. The particle can entrap CBD, making its way to target cells unnoticed by the body's immune system, and then release its load when excited by an exogenous light source with high intensity - a laser. Targeted therapies such as this warrant further exploration because they can be used to stimulate apoptosis and synthesize reactive oxygen species within the cancer cell, thus eliciting a synergistic destructive effect. ${ }^{35}$ Poly- $\varepsilon$-Caprolactone microspheres have shown great promise as a sustained release formulation; essentially, the study found that the formulation shows a peak of release at 4-7 days which slows after 7 days. Sustained-release cannabinoids should be further explored in application against cancer as anti-cancer growth agents. ${ }^{36}$ PTL101 Oromucosal Spray shows increased bioavailability compared to preexisting oromucosal sprays. A safe and tolerable formulation could be indicated for use in other treatment plans, specifically in treating pain and nausea in chemotherapy patients. ${ }^{69}$ PTL401 is a pro-nano dispersion technology that showed $30 \%$ improvement in $\mathrm{C}_{\max }$ compared to traditional formulations and halved $\mathrm{T}_{\max }$ consistently. ${ }^{38}$ This adds to the body of information, which indicates that self-emulsifying agents and emulsion formulations are superior to traditional formulations. Poly (lactic-co-glycolic acid) based nanoparticles were able to show significantly slowed release in in-vivo studies while simultaneously showing a 2.2 -fold reduction in tumor volume. PEG-PLGA NPs could therefore serve as agents to reduce tumor size, indicating a possible use as adjunctive agents in chemotherapy $^{39}$. They could serve as sustained release formulations in medical, supplemental, or recreational capacities from a drug delivery perspective. PNL formulations resulted in a 6fold AUC increase compared to the traditional CBD solution analyzed. This formulation is novel because it uses piperine, a molecule known for its inhibitory effect. Future $\mathrm{CBD} / \mathrm{THC}$ formulations could utilize piperine as a simple biological hack, disabling liver enzymes responsible for metabolism, functionally slowing metabolism, and then increasing serum concentrations as a downstream effect. ${ }^{40}$ This is a suggested conclusion for ethylcellulose and 
electrospun fibers containing pyrrolidone, having excellent dreg loading at $80 \%$ and $90 \%$, respectively. ${ }^{44,47}$ Classically, buccal or sublingual formulations are thought to increase serum concentrations the most and most rapidly. Compared to buccal spray, PNL formulations showed a 3 -fold increase in $\mathrm{C}_{\max }$ and a 1.5 -fold increase in AUC. ${ }^{41}$ The overwhelming support of the efficacy of PNL formulations utilizing piperine. Nanostructured lipid carriers have shown a 10 -fold increase in loading capacity, indicating a possible therapeutic carrier to be explored in the future ${ }^{42,43}$. Calcium Alginate Liposomal Suspension has shown significant promise as a sustained release and timed-release formulation - while also exhibiting dosespecific accuracy. This nanogel formulation should be further explored, showing significant and novel accuracy. Nasal and mucoadhesive silica were both excellent drug loading but were not assessed in animal models. The mucoadhesive silica was the only one that tested on actual cell lines, but neither study assessed the CBD drug disposition in living models. ${ }^{45,46}$ The nasal mucosal agent was seen to have a positive charge with a zeta potential of $41 \pm 0.6 \mathrm{mV}$. It has excellent potential to bind to negatively charged buccal cells, but it needs to be tested in animal models to confirm their hypothesis ${ }^{46}$.

\section{Miscellaneous Dosage Forms}

Several CBD formulations that were analyzed did not fit into any of the previous categories. These included a vaporized, intravenous, and smoked formulations. IV-CBD showed value in that it achieved peak plasma concentrations in just 10 minutes, compared to the 80 -minute $\mathrm{T}_{\max }$ of oral formulations. IV-CBD also showed significant anti-depressive action while maintaining plasma concentrations comparable to oral formulations for up to 12 hours. ${ }^{70}$ IV-CBD may be ideal for exploration as therapeutics in depressed and anxious states. The study of vaporized CBD in rats showed little significance. While it did indicate a significant drop in core body temperature of the rats, there is no clear evidence this was due solely to the CBD. However, if it is, reducing core body temperature could indicate possible use as an antipyretic; from this perspective, the study's findings should be further evaluated. ${ }^{48}$ Finally, the study of smoked cannabis yielded unremarkable results. ${ }^{50}$ Essentially, the study found that CBD, $\mathrm{CBN}$, and THC-glucuronide could be used as inclusionary markers of recent use. This is unremarkable because current strategies in drug testing analyze levels of THC-COOH to the $10-$ $500 \mathrm{ng} / \mathrm{mL}$ level in urine. Based on standardized curves, they can tell with relative accuracy how recently someone has used cannabis. ${ }^{71}$ It was clear the study's goal was to find biomarkers that could indicate recent use in the range of hours, but the findings do not indicate that could be done accurately. ${ }^{50}$

\section{Conclusions}

The current state of cannabinoid drug delivery platforms is evolving. Each system has its advantages and disadvantages. Some have been examined in human clinical settings, whereas others have been tested at the experimental level to acceptable veracity. The difference in value is that one has been tested in the target demographic while the other must still undergo that step to examine its versatility in that population. However, as far as drug delivery and biodistribution are concerned, animal models remain an adequate gauge to mark the viability of a possible human trial with the compound in question. Overall, in this respect, one can expect that adequately showing an increase of CBD in plasma concentration in animal models with a given dosage form in contrast to a conventional dosage form is an indication of bioavailability enhancement. It is then thought this enhancement of bioavailability could then carry over to function similarly in human models. While many of these techniques show promise, an overarching theme encompasses their effectiveness. Generally, emulsion-based formulations encapsulate lipophilic CBD and improve serum concentrations of $\mathrm{CBD}$, decrease the time to attain this maximum concentration, and prolong the effect. These pros can be observed in all emulsion-based formulations and many nanoparticle formulations that utilize emulsions as carrier systems. Essentially, the liposphere formulations hijack bile-acid sequestration of fatty acid micelles. As demonstrated by Nakano et al., bile fistulated rats showed no difference in absorbance for the nano-emulsion formulation they examined when compared to traditional non-salted formulations. Current patents that revolve around emulsions, nano-salts, micelle, and liposphere formulations will likely display similar increased serum concentrations and time to reach these levels when examined correctly in laboratory and clinical conditions. 
Nanoparticle formulations show the greatest ability to achieve sustained release effects and maximize serum concentrations compared to conventional oral lipid formulations. Explorations into using cannabinoids as adjunctive therapeutics in chemotherapy have shown that CBD displays synergistic effects when combined with chemotherapeutic agents like paclitaxel and doxorubicin; specifically, they were able to show increases in cancer cell apoptosis. In similar studies, adjunctive therapy with sustained-release CBD was found to reduce tumor volume when compared to chemotherapy alone. Overall, other nanoparticle formulations that measured $\mathrm{AUC}$ and $\mathrm{C}_{\max }$ consistently showed large increases in both compared to conventional MCT lipid formulations.

Topical formulations have shown some promise in achieving high serum concentrations of cannabinoids; however, overcoming the lipophilicity of CBD is an ongoing process. One of the examples is CBD suspended in nano-hydrogels for transdermal application of drug delivery technology. This drug delivery methodology would allow for the titration of specific cannabinoid doses over hours and days. Many explorations of the application of cannabinoids in chemotherapy have shown that prolonging the dose of cannabinoids decreases tumor size and assists in the apoptosis of cancer cells. Therefore, a transdermal delivery method that ensures consistent levels of cannabinoids in serum concentration without consecutive dosing may prove beneficial. Applications of this technology should be explored to show its possible benefit as an adjunct to chemotherapy.

Of the conventional formulations, a few novel applications of CBD have also been proposed and show promise in their specified field. The application of CBD in the de-escalation of opioid use in patients is an important area. The use of opioids in pain management will not go away anytime soon; therefore, helping patients ween off the medications effectively when needed can reduce recidivism rates to opioid use or possible abuse. The use of subcutaneous CBD in the management of obesity has demonstrated interesting results. Like the opioid health crisis, obesity on a global stage can be described as a health crisis. The possibility of helping individuals manage this disease state offers both large markets for exploitation and a great benefit to human well-being. Finally, conventional formulations already approved by the FDA like nabiximol and dronabinol have been investigated for use in treating cannabis withdrawal symptoms, with the results favoring the former. The ability to treat patients with psychological cannabis dependence will help advance mental well-being and further support an investigative market in developing cannabis-based anti-anxiolytics and antidepressant medications. Overall, conventional MCT/lipid formulations which do not apply novel methodologies in drug delivery still manage to achieve notable serum concentrations. However, they are often used as a baseline to demonstrate just how much more effective other novel formulations being examined are.

Cannabinoids display potential as adjunctive therapies within the scope of several disease states. Likewise, they demonstrate potential use in managing inflammation, depression, and anxiety. The appropriate dosage form selection depends on the disease state and patient compliance. In this regard, there may be a place to distinguish the usefulness of specific dosage forms over others. In general, bioavailability, the volume of distribution, first-pass metabolism, length of effect, stability, and organ-specific targeting are factors that can be manipulated by dosage form preparation. In general, drug delivery systems entrap or encapsulate CBD. It is expected that this would increase its stability compared to conventional dosage forms. Nonetheless, each formulation must be tested for its stability as per FDA guidelines. All these avenues require further clinical research to evaluate the value of these medications to patients. 


\section{Future Aspects of Cannabinoids}

The future of cannabinoids and their use in clinical settings is uncertain. While many studies have shown the products display value and eclectic usages, state and federal laws still need to catch up to the science. ${ }^{2}$ Several investigational drug studies have started applying cannabinoids or derivatives as antianxiolytics and antidepressant medications. ${ }^{72,73}$ Additionally, the use of cannabinoids and their innate anti-inflammatory impact is being explored; while every anti-inflammatory medication has an upper tolerability threshold, cannabinoids have been shown to be widely tolerable. ${ }^{74,75}$ The use of CBD in treating specific seizure types has been evaluated and accepted by the FDA. ${ }^{19}$ Most cannabinoids are not psychoactive, and psychoactive cannabinoids themselves could act as promising vectors for treating psychological and neurological disorders. ${ }^{72,73}$ Therefore, limiting the scope of cannabinoid applications despite the abundance of data supporting further research may not be as prudent as once thought.

\section{Acknowledgments:}

Authors would like to acknowledge Dean George E. MacKinnon III, Ph.D., MS, RPh, FASHP, FNAP, School of Pharmacy, Medical College of Wisconsin for providing support.

\section{Funding}

This research did not receive any specific grant funding agencies in the public, commercial, or notfor-profit sectors.

\section{Conflict of interest}

The authors declare no conflict of interest. For signed statements, please contact the journal office: editor@precisionnanomedicine.com

Quote this article as Sperry AJ, Youssef T, Tuong Y, Chauhan AS, A Systematic Review of Cannabidiol Based Dosage Forms, https://doi.org/10.33218/001c.30706 Precis. Nanomed. 2021;4(4):851878.

\section{References}

1. Agriculture USD of. Full CBD Manuscript. 2018.

2. 1. Office of the Commissioner. FDA Regulation of Cannabis and Cannabis-Derived Products: Q\&A. US Food Drug Adm. Published online 2021.

3. Lucas CJ, Galettis P SJ. The pharmacokinetics and the pharmacodynamics of cannabinoids. $\mathrm{Br}$ J Clin Pharmacol. 2018;84(11):2477-2482. doi:10.1111/bcp.13710

4. Pertwee RG. The diverse $\mathrm{CB} 1$ and $\mathrm{CB} 2$ receptor pharmacology of three plant cannabinoids: delta9-tetrahydrocannabinol, cannabidiol,, and delta9-tetrahydrocannabivarin. Br J Pharmacol. 2008;153(2):199-215. doi:10.1038/sj.bjp.0707442

5. Muller C, Morales P RP. Cannabinoid Ligands Targeting TRP Channels. Front Mol Neurosci. 2019;11:487. doi:10.3389/fnmol.2018.00487

6. Millar SA, Stone NL, Yates AS OS. A Systematic Review on the Pharmacokinetics of Cannabidiol in Humans. Front Pharmacol. 2018;9:1365. doi:10.3389/fphar.2018.01365

7. Bruni N, Della Pepa C, Oliaro-Bosso S, Pessione E, Gastaldi D DF. Cannabinoid Delivery Systems for Pain and Inflammation Treatment. Molecules. 2018;23(10):2478. doi:10.3390/molecules 23102478

8. E P. Cannabinoids in the Treatment of Epilepsy: Hard Evidence at Last? J Epilepsy Res. 2017;7(2):61-76. doi:10.14581/jer.17012

9. Elikkottil J, Gupta P GK. The analgesic potential of cannabinoids. J Opioid Manag. 2010;6(1):14.

10. Kleckner AS, Kleckner IR, Kamen CS et al. Opportunities for cannabis in supportive care in cancer. Ther Adv Med Oncol. 2019;11. doi:10.1177/1758835919866362

11. Millar SA, Stone NL, Bellman ZD, Yates AS, England TJ, O’Sullivan SE. A systematic review of cannabidiol dosing in clinical populations. Br J Clin Pharmacol. 2019;85(9):1888-1900. doi:10.1111/bcp.14038 
12. Chang RK, Raw A, Lionberger R YL. Generic development of topical dermatologic products: formulation development, process development, and testing of topical dermatologic products. AAPS J. 2015;17(6):1522. doi:10.1208/s12248-012-9411-0

13. Williamson EM, Evans FJ. Cannabinoids in clinical practice. Drugs. 2000;60(6):1303-1314. doi:10.2165/00003495-200060060-00005

14. Millar S, Maguire R, Yates A, O'Sullivan S. Towards Better Delivery of Cannabidiol (CBD). Pharmaceuticals. 2020;13(9):219. doi:10.3390/ph13090219

15. de Jong W BP. Drug delivery and nanoparticles: Applications and hazards. Int J Nanomedicine. 2008;133. doi:10.2147/ijn.s596

16. Allsop D, Lintzeris N, Copeland J, Dunlop A MI. Cannabinoid replacement therapy (CRT): Nabiximols (Sativex) as a novel treatment for cannabis withdrawal. Clin Pharmacol Ther. 2015;97(6):571-574. doi:10.1002/cpt.109

17. Birnbaum AK, Karanam A, Marino SE, et al. Food effect on pharmacokinetics of cannabidiol oral capsules in adult patients with refractory epilepsy. Epilepsia. 2019;60(8):1586-1592. doi:10.1111/epi.16093

18. Vaughn D, Kulpa J, Paulionis L. Preliminary Investigation of the Safety of Escalating Cannabinoid Doses in Healthy Dogs. Front Vet Sci. 2020;7(February):1-13. doi:10.3389/fvets.2020.00051

19. Inc GB. Epidiolex. Published online 2018.

20. Roberts I, Shakur-Still H, Aeron-Thomas A, et al. Effects of tranexamic acid on death, disability, vascular occlusive events and other morbidities in patients with acute traumatic brain injury (CRASH-3): A randomised, placebo-controlled trial. Lancet. 2019;394(10210):1713-1723. doi:10.1016/S0140-6736(19)32233-0

21. Capano A, Weaver R, Burkman E. Evaluation of the effects of CBD hemp extract on opioid use and quality of life indicators in chronic pain patients: a prospective cohort study. Postgrad Med. 2020;132(1):56-61. doi:10.1080/00325481.2019.1685298

22. Nitecka-Buchta A, Nowak-Wachol A, Wachol K et al. Myorelaxant Effect of Transdermal Cannabidiol Application in Patients with TMD: A Randomized, Double-Blind Trial. J Clin Med. 2019;8(11):1886. doi:10.3390/jcm8111886

23. Giacoppo S, Galuppo M, Pollastro F, Grassi G, Bramanti P, Mazzon E. A new formulation of cannabidiol in cream shows therapeutic effects in a mouse model of experimental autoimmune encephalomyelitis. DARU, J Pharm Sci. 2015;23(1):1-17. doi:10.1186/s40199-015-0131-8

24. Lodzki M, Godin B, Rakou L, Mechoulam R, Gallily R, Touitou E. Cannabidiol - Transdermal delivery and anti-inflammatory effect in a murine model. J Control Release. 2003;93(3):377387. doi:10.1016/j.jconrel.2003.09.001

25. Walter H. Wallace. Method of Relieving Analgesia and Reducing Inflammation Using a Cannabinoid Delivery Topical Liniment. Published online 2005.

26. Gary Allen Lowe VL. Composition of cannabinoids, odorous volatile compounds, and emu oil for topical application, and a method for cannabinoid transdermal delivery. Online in 2015.

27. Audra Lynn Stinchcomb, Stan Lee Banks, Miroslaw Jerzy Golinski, Jeffery Lynn Howard DCH. Use of cannabidiol prodrugs in topical and transdermal administration with microneedles. Published online 2014.

28. Musazzi U, Ortenzi M, Gennari C, Casiraghi A, Minghetti P, Cilurzo. Design of pressure-sensitive adhesive suitable for the preparation of transdermal patches by hot-melt printing. Int $\mathrm{J}$ Pharm. 2020;586(119607):1-9. doi:10.1016/j.ijpharm.2020.119607

29. Dirksen M, Kinder T, Brandel T, Hellewig T. Temperature Controlled Loading and Release of the Anti-Inflammatory Drug Cannabidiol by Smart Microgels. Molecules. 2021;26(3181):2-23. doi:10.3390/molecules26113181

30. Knaub K, Sartorius T, Dharsono T, Wacker R, Wilhelm M, Schön C. A novel self-emulsifying drug delivery system (SEDDS) based on Vesisorb ${ }^{\circledR}$ formulation technology improving the oral 
bioavailability of cannabidiol in healthy subjects. Molecules. 2019;24(16). doi:10.3390/molecules24162967

31. Nakano Y, Tajima M, Sugiyama E, Sato VH, Sato H. Development of a Novel Nano-emulsion Formulation to Improve Intestinal Absorption of Cannabidiol. Med Cannabis Cannabinoids. 2019;2(1):35-42. doi:10.1159/000497361

32. Donna K. Jackson KH. Silicone and Hyaluronic Acid (HLA) Delivery Systems for Products by Sustainable Processes for Medical Uses Including Wound Management. Published online 2013.

33. Jirí Skalicky, Jirí Husek, Jana Hofbauerová MD. A composition for the treatment of inflammatory diseases comprising boswellic acids and cannabidiol. Published online 2011.

34. Fraguas-Sánchez AI, Fernández-Carballido A, Simancas-Herbada R, Martin-Sabroso C, TorresSuárez AI. CBD loaded microparticles as a potential formulation to improve paclitaxel and doxorubicin-based chemotherapy in breast cancer. Int J Pharm. 2020;574(November 2019):118916. doi:10.1016/j.ijpharm.2019.118916

35. Mokoena DR, George BP, Abrahamse H. Enhancing breast cancer treatment using a combination of cannabidiol and gold nanoparticles for photodynamic therapy. Int J Mol Sci. 2019;20(19). doi:10.3390/ijms20194771

36. Hernan Perez De La Ossa D, Ligresti A, Gil-Alegre ME, et al. Poly- $\varepsilon$-caprolactone microspheres as a drug delivery system for cannabinoid administration: Development, characterization and in vitro evaluation of their antitumoral efficacy. J Control Release. 2012;161(3):927-932. doi:10.1016/j.jconrel.2012.05.003

37. Effects AD. 2020 Annual Meeting American College of Clinical Pharmacology®. Clin Pharmacol drug Dev. 2020;9:1-75. doi:10.1002/cpdd.858

38. Atsmon J, Cherniakov I, Izgelov D, et al. PTL401, a New Formulation Based on Pro-Nano Dispersion Technology, Improves Oral Cannabinoids Bioavailability in Healthy Volunteers. J Pharm Sci. 2018;107(5):1423-1429. doi:10.1016/j.xphs.2017.12.020

39. Martín-Banderas L, Muñoz-Rubio I, Prados J, et al. In vitro and in vivo evaluation of $\Delta 9$-tetrahidrocannabinol/PLGA nanoparticles for cancer chemotherapy. Int J Pharm. 2015;487(12):205-212. doi:10.1016/j.ijpharm.2015.04.054

40. Cherniakov I, Izgelov D, Domb AJ, Hoffman A. The effect of Pro NanoLipospheres (PNL) formulation containing natural absorption enhancers on the oral bioavailability of delta-9-tetrahydrocannabinol (THC) and cannabidiol (CBD) in a rat model. Eur $J$ Pharm Sci. 2017;109(July):21-30. doi:10.1016/j.ejps.2017.07.003

41. Cherniakov I, Izgelov D, Barasch D, Davidson E, Domb AJ, Hoffman A. Piperine-pro-nanolipospheres as a novel oral delivery system of cannabinoids: Pharmacokinetic evaluation in healthy volunteers in comparison to buccal spray administration. J Control Release. 2017;266(September):1-7. doi:10.1016/j.jconrel.2017.09.011

42. Esposito E, Drechsler M, Cortesi R, Nastruzzi C. Encapsulation of cannabinoid drugs in nanostructured lipid carriers. Eur J Pharm Biopharm. 2016;102:87-91. doi:10.1016/j.ejpb.2016.03.005

43. Monshipouri M RA. Liposome-encapsulated alginate: controlled hydrogel particle formation and release. J Microencapsul. 1995;12(2):117-127. doi:10.3109/02652049509015282

44. Andriotis E, Chachlioutaki K, Monou PK, et al. Development of Water-Soluble Electrospun Fibers for the Oral Delivery of Cannabinoids. Am Assoc Pharm Sci. 2021;22(23):1-14. doi:10.1208/s12249-020-01895-7

45. Sopper U, Hoffmann A, Daniels R. Mucoadhesion and Mucopenetration of Cannabidiol (CBD)Loaded Mesoporous Carrier Systems for Buccal Drug Delivery. Sci Pharm. 2021;89(35):1-15. doi:10.3390/scipharm89030035

46. Matarazzo A, Silvestre L, Carvalho F, et al. Mucoadhesive nanostructured lipid carriers as a cannabidiol nasal delivery system for the treatment of neuropathic pain. Eur J Pharm Sci. 2021;159:928-987. doi:10.1016/j.ejps.2020.105698

47. Zamansky M, Zehavi N, Ben-Shabat S, Sintov A. Characterization of Nanoparticles made of 
Ethyl Cellulose and Stabilizing Lipids: Mode of Manufacturing, Size Modulation, and Study of their Effect on Keratinocytes. Int J Pharm. 2021;21:1-41. doi:10.1016/j.ijpharm.2021.121003

48. Javadi-Paydar M, Creehan KM, Kerr TM, Taffe MA. Vapor inhalation of cannabidiol (CBD) in rats. Pharmacol Biochem Behav. 2019;184(July):172741. doi:10.1016/j.pbb.2019.172741

49. Xu C, Chang T, Du Y, Yu C, Tan X LX. Pharmacokinetics of oral and intravenous cannabidiol and its antidepressant-like effects in chronic mild stress mouse model. Env Toxicol Pharmacol. 2019;70(103202). doi:10.1016/j.etap.2019.103202

50. Desrosiers NA, Himes SK, Scheidweiler KB, Concheiro-Guisan M, Gorelick DA, Huestis MA. Phase $\mathrm{i}$ and ii cannabinoid disposition in blood and plasma of occasional and frequent smokers following controlled smoked cannabis. Clin Chem. 2014;60(4):631-643. doi:10.1373/clinchem.2013.216507

51. Devinsky O, Kraft K, Rusch L, Fein M, Leone-Bay A. Improved Bioavailability with Dry Powder Cannabidiol Inhalation: A Phase 1 Clinical Study. J Pharm Sci. Published online 2021. doi:10.1016/j.xphs.2021.08.012

52. Uziel A, Gelfand A, Amsalem K, et al. Full-Spectrum Cannabis Extract Microdepots Support Controlled Release of Multiple Phytocannabinoids for Extended Therapeutic Effect. ACS App1 Mater Interfaces. 2020;12:23707-23716. doi:10.1021/acsami.0c04435

53. Holmes Organics CBD. Buy CBD Online - Organic CBD Oil - Black-Owned.

54. Saha Editorial Team. Saha Self Care. A Premium CBD Self-care Company. Accessed February 9, 2021. https://sahaselfcare.com/

55. Sunoil. Sunsoil. Published 2020. Accessed September 6, 2021. https://www.sunsoil.com/

56. Charlottesweb.com. Charlotte's WebTM CBD Oil, CBD Gummies and Cream Official Site. Published 2021. Accessed August 20, 2021. https://www.charlottesweb.com/

57. Joy Organics. Organics J. Joy Organics - Premium, Organic CBD Oil Products. Published 2021. Accessed September 2, 2021. https://joyorganics.com/

58. Medicinals R. R+R Medicinals: The CBD That Works. Published 2019. Accessed September 3, 2021. https://www.rrmeds.com/

59. Cornbreadhemp.com. Cornbread HempTM - Full Spectrum CBD Oils, Gummies, and Topicals. Published 2019. Accessed August 21, 2021. https://www.cornbreadhemp.com/

60. Medterra CBD LLC. Medterra. Published 2021. Accessed August 31, 2021. https://medterracbd.com/

61. Bonnet U, Preuss U. The cannabis withdrawal syndrome: current insights. Subst Abuse Rehabil. 2017; Volume 8:9-37. doi:10.2147/sar.s109576

62. Zgair A, Lee JB, Wong JCM, et al. Oral administration of cannabis with lipids leads to high levels of cannabinoids in the intestinal lymphatic system and prominent immunomodulation. Sci Rep. 2017;7(1):1-12. doi:10.1038/s41598-017-15026-Z

63. Grand View Research. Pet Supplements Market Share.

64. Rossi F, Punzo F, Umano GR, Argenziano M MDGE. Role of Cannabinoids in Obesity. Int J Mol Sci. 2018;19(9):2690. doi:10.3390/ijms19092690

65. Business Wire. Global Weight Loss Supplement Market 2020-2024.; 2020.

66. Dasgupta N, Beletsky L CD. Opioid Crisis: No Easy Fix to Its Social and Economic Determinants. Am J Public Heal. 2018;108(2):182-186. doi:10.2105/AJPH.2017.304187

67. Vigata M, Meinert C, Hutmacher DW BN. Hydrogels as Drug Delivery Systems: A Review of Current Characterization and Evaluation Techniques. Pharmaceutics. 2020;12(12):1118. doi:10.3390/pharmaceutics 12121188

68. Izgelov D, Shmoeli E, Domb AJ, Hoffman A. The effect of medium chain and long chain triglycerides incorporated in self-nano emulsifying drug delivery systems on oral absorption of cannabinoids in rats. International Journal Pharm. 2020;580(March):119201. doi:10.1016/j.ijpharm.2020.119201

69. Atsmon J, Heffetz D, Deutsch L, Deutsch F, Sacks H. Single-Dose Pharmacokinetics of Oral 
Cannabidiol Following Administration of PTL101: A New Formulation Based on Gelatin Matrix Pellets Technology. Clin Pharmacol Drug Dev. 2018;7(7):751-758. doi:10.1002/cpdd.408

70. Yamamoto H, Kuno Y, Sugimoto S, Takeuchi H, Kawashima Y. Surface-modified PLGA nanosphere with chitosan improved pulmonary delivery of calcitonin by mucoadhesion and opening of the intercellular tight junctions. J Control Release. 2005;102(2):373-381. doi:10.1016/j.jconrel.2004.10.010

71. Goodwin RS, Darwin WD, Chiang CN, Shih M, Li SH HM. Urinary elimination of 11-nor-9carboxy-delta9-tetrahydrocannnabinol in cannabis users during continuously monitored abstinence. J Anal Toxicol. 2008;32(8):562-569. doi:10.1093/jat/32.8.562

72. Shannon S, Lewis N, Lee H, Hughes S. Cannabidiol in Anxiety and Sleep: A Large Case Series. Perm J. 2019;23:18-041. doi:10.7812/TPP/18-041

73. Fogaça MV, Galve-Roperh I, Guimarães FS CA. Cannabinoids, Neurogenesis and Antidepressant Drugs: Is there a Link? Curr Neuropharmacol. 2013;11(3):263-275. doi:10.2174/1570159X11311030003

74. Nagarkatti P, Pandey R, Rieder SA, Hegde VL NM. Cannabinoids as novel anti-inflammatory drugs. Futur Med Chem. 2009;1(7):1333-1349. doi:10.4155/fmc.09.93

75. Larsen C SJ. Dosage, Efficacy and Safety of Cannabidiol Administration in Adults: A Systematic Review of Human Trials. J Clin Med Res. 2020;12(3):129-141. doi:10.14740/jocmr4090 